

\section{The Sulfonylurea Drug, Glimepiride, Stimulates Glucose Transport, Glucose Transporter Translocation, and Dephosphorylation In Insulin-Resistant Rat Adipocytes In Vitro \\ GÜNTER MÜLLER AND SUSANNE WIED}

Sulfonylurea drugs are widely used in the therapy of NIDDM. The improvement of glucose tolerance after long-term treatment of NIDDM patients with the drug can be explained by stimulation of glucose utilization in peripheral tissues that are characterized by insulin resistance in these patients. We studied whether the novel sulfonylurea drug, glimepiride, stímulates glucose transport into isolated insulin-resistant rat adipocytes. After long-term incubation of the cells in primary culture with high concentrations of glucose, glutamine, and insulin, stimulation of glucose transport by insulin was significantly reduced both with respect to maximal responsiveness $(65 \%$ decrease of $\left.V_{\max }\right)$ and sensitivity (2.6-fold increase of $E D_{50}$ ) compared with adipocytes cultured in medium containing a low concentration of glucose and no insulin. This reflects insulin resistance of glucose transport. In contrast, both responsiveness and sensitivity of glucose transport toward stimulation by glimepiride were only marginally reduced in insulin-resistant adipocytes $\left(15 \%\right.$ decrease of $V_{\text {max }}$; 1.2-fold increase of $E_{50}$ ) versus control cells. Glimepiride, in combination with glucose and glutamine during the primary culture, caused desensitization of the glucose transport system toward stimulation by insulin, but to a lesser degree than insulin itself $\left(50 \%\right.$ reduction of $V_{\text {max }}$; ninefold increase of $\left.E D_{50}\right)$. Again, the maximal responsiveness and sensitivity of glucose transport toward stimulation by

\footnotetext{
From the Hoechst Aktiengesellschaft Frankfurt, Frankfurt, Germany.

Address correspondence and reprint requests to Dr. Günter Müller, c/o Hoechst AG Frankfurt am Main Pharmaceutical Research Divison, SBU Metabolic Diseases H 825, D-65926 Frankfurt am Main, Germany.

Received for publication 15 September 1992 and accepted in revised form 8 July 1993.

NIDDM, non-insulin-dependent diabetes mellitus; DMEM, Dulbecco's modified 'Eagle's medium; HBSS, HEPES-based balanced salt solution; PMSF, phenylmethylsulfonyl fluoride; LDM, low-density microsomes; PM, plasma membrane; GLUT, glucose transporter isoform; STZ, streptozocin; SDS-PAGE, sodium dodecyl sulfate-polyacrylamide gel electrophoresis; PBS, phosphate-buffered saline; BSA, bovine serum albumin; KRBB, KrebsRinger bicarbonate buffer; FCS, fetal calf serum; $\beta$-COP, $\beta$-coat protein; TCA, trichloroacetic acid; IgG, immunoglobulin G; PKA, protein kinase $A ; P K C$, protein kinase C; IGF-II, insulin-like growth factor II.
}

glimepiride were only slightly diminished. The presence of glimepiride during primary culture did not antagonize the induction of insulin resistance of glucose transport. The stimulation of glucose transport in insulin-resistant adipocytes by glimepiride is caused by translocation of glucose transporters from low-density microsomes to plasma membranes as demonstrated by subcellular fractionation and immunoblotting with anti-GLUT1 and anti-GLUT4 antibodies. Immunoprecipitation of GLUT4 from ${ }^{32}$ Piand $\left[{ }^{35}\right.$ S]methionine-labeled adipocytes revealed that the insulin resistance of GLUT4 translocation is accompanied by increased (three- to fourfold) phosphorylation of GLUT4 in both low-density microsomes and plasma membranes. Short-term treatment of desensitized adipocytes with glimepiride or insulin reduced GLUT4 phosphorylation by $\sim 70$ and $25 \%$, respectively, in both fractions. We conclude that glimepiride activates glucose transport by stimulation of GLUT1 and GLUT4 translocation in rat adipocytes via interference at a site downstream of the putative molecular defect in the signaling cascade between the insulin receptor and the glucose transport system induced by high concentrations of glucose and insulin. The molecular site of glimepiride action is related to GLUT4 phosphorylation/dephosphorylation, which may regulate glucose transporter activity and translocation. These in vitro findings implicate an additional mode of sulfonylurea action in the improvement of glucose tolerance of NIDDM patients. Diabetes 42:1852-67, 1993

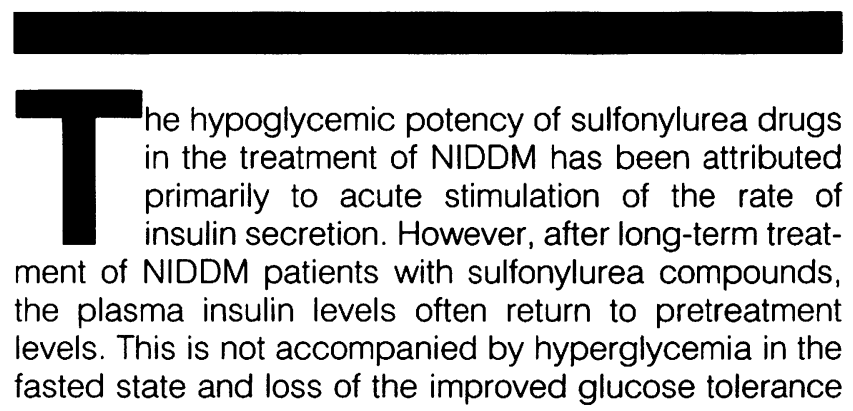


$(1,2)$. Euglycemic clamp studies revealed that sulfonylurea compounds increase insulin-induced glucose utilization in normal rats $(3)$ and NIDDM patients $(4,5)$. These observations may be taken as an indication for extrapancreatic effects of sulfonylurea drugs. However, because of the presence of insulin under these experimental conditions it is difficult to determine the reasons for the increased glucose clearance rates. The compounds either directly stimulate rate-limiting steps of glucose metabolism or enhance their insulin sensitivity or improve the overall metabolic situation in peripheral tissues because of increased insulin and reduced glucose levels. In vitro studies are useful to discriminate between these possibilities.

Numerous in vitro studies using normal cells demonstrated that sulfonylurea drugs directly stimulate glucose metabolizing steps, i.e., glycogen synthesis in rat adipocytes (6) and glucose transport in $\mathrm{BC} 3 \mathrm{H}-1$ myocytes $(7,8)$, L6 myocytes (9), 3T3-LI adipocytes (10), and isolated rat adipocytes $(11,12)$. Furthermore, sulfonylurea drugs enhance the action of exogeneous insulin in depancreatized dogs (13) and potentiate the insulin stimulation of muscle glycogen synthase in NIDDM patients (14). The sulfonylurea-induced enhancement of insulin action could be mimicked in vitro using adipocytes and hepatocytes from STZ-induced diabetic rats. Glyburide potentiated insulin-stimulated but not basal glucose transport (15), and tolazamide increased insulinsensitive but not basal lipogenesis (16). This suggests that in the absence of insulin, sulfonylurea drugs exert no direct effect on insulin-resistant peripheral and liver cells.

However, the insulin-resistant state evolving during the pathogenesis of NIDDM is characterized by hyperinsulinemia. A large body of experimental evidence points to significant differences in the genesis and characteristics of insulin resistance induced and accompanied by hypoand hyperinsulinemia (17-20). Therefore, the question emerged whether sulfonylurea drugs exert direct effects on peripheral cells that display insulin resistance induced by hyperinsulinemia. Previously, Marshall et al. (21) introduced a model system for the induction of insulin resistance in vitro by incubation of fat cells in a diabetic (hyperinsulinemic and hyperglycemic) milieu characteristic for NIDDM (22). After $20 \mathrm{~h}$ of primary culture with high concentrations of glucose, glutamine, and insulin, freshly isolated rat adipocytes exhibited a significantly reduced maximal insulin responsiveness and sensitivity of the initial glucose transport velocity. This state is defined as insulin resistance of glucose transport.

Herein, we used this method to study whether the novel sulfonylurea drug, glimepiride, directly stimulates glucose transport in insulin-resistant rat adipocytes. Glimepiride was chosen because Geisen (23) showed that in dogs this drug had a long-lasting hypoglycemic effect without markedly elevated plasma insulin levels, suggesting a very efficient extrapancreatic action. We observed a significant direct stimulation of glucose transport and GLUT1 and GLUT4 translocation in insulinresistant adipocytes by this drug. We then studied the possible mechanism of desensitization of the glucose transport system toward insulin and of glucose transport stimulation by glimepiride. Phosphorylation of components of signal transduction cascades has been implicated as a mechanism of desensitization of diverse signaling pathways $(24,25)$. Therefore, we asked whether the glucose transporter, a component of the insulin signaling cascade, is also a target for phosphorylation during induction of insulin resistance of glucose transport in primary cultured adipocytes. In fact, we observed increased GLUT4 phosphorylation under these conditions. The phosphorylation state of GLUT4 becomes reduced by acute glimepiride treatment. The possible implications for the therapy of NIDDM with sulfonylurea drugs are discussed.

\section{RESEARCH DESIGN AND METHODS}

Radiochemicals and affinity-purified $\left[{ }^{125} \mid\right]$ protein A (30 $\mathrm{mCi} / \mathrm{mg}$ ), polyclonal and donkey anti-rabbit $\left[{ }^{125} \mathrm{l}\right] \mathrm{lgG}$, nitrocellulose sheets Hybond $C$ extra, and scintillation cocktail ACSII were bought from Amersham-Buchler (Braunschweig, Germany); goat anti-rabbit IgG coupled to alkaline phosphatase were provided by Sigma (Deisenhofen, Germany); dinonylphthalate oil was from Merck (Darmstadt, Germany); reagents for cell culture were obtained from Gibco-BRL (Eggenstein-Leopoldshafen, Germany); collagenase type CLS II was bought from Worthington (Freehold, NJ); protein A-Sepharose was provided by LKB/Pharmacia (Freiburg, Germany); and polyclonal rabbit anti-GLUT4 antibodies raised against purified rat GLUT4 were provided by Calbiochem (Bad Soden, Taunus, Germany). Peptide anti-GLUT4 antibodies were obtained from a rabbit injected with a peptide corresponding to the $\mathrm{COOH}$-terminal 16 amino acids of rat GLUT4 (26) and coupled to keyhole limpet hemocyanin, and the rabbit anti-GLUT1 antiserum was raised against a peptide corresponding to the $\mathrm{COOH}$ terminal 12 amino acids of the human GLUT1 sequence (27). Both antibodies were affinity-purified. Polyclonal anti-rat $\beta$-COP and anti-rat $\mathrm{Na}^{+}-\mathrm{K}^{+}-$ATPase ( $\alpha$-subunit) antisera from rabbit were gifts from Dr. T. Kreis, Heidelberg, and Dr. G.V. Jagow, Frankfurt, Germany, respectively. Semisynthetic human insulin and glimepiride (HOE 490) were prepared by the Pharma Synthesis Department of Hoechst Aktiengesellschaft, Frankfurt; glimepiride was dissolved in $25 \mathrm{mM} \mathrm{HEPES} / \mathrm{KOH}(\mathrm{pH} 7.4)$ at a 2 $\mathrm{mM}$ stock solution made daily.

Preparation of rat adipocytes. Adipocytes were isolated from epididymal fat pads of 160 - to $180 \mathrm{-g}$ male Wistar rats under sterile conditions as described previously (28) with the following modifications: Cut tissue pieces were incubated for $20 \mathrm{~min}$ at $37^{\circ} \mathrm{C}$ with collagenase $(1 \mathrm{mg} / \mathrm{ml})$ in KRBB, $25 \mathrm{mM} \mathrm{HEPES} / \mathrm{KOH}(\mathrm{pH} 7.4)$, $0.1 \mathrm{mM}$ glucose, $1 \% \mathrm{wt} / \mathrm{vol}$ BSA. The cell suspension was filtered through a $100-\mu \mathrm{m}$ nylon screen, washed 3 times by flotation (accumulation in a thin cell layer on top of the medium after centrifugation at $1000 \mathrm{~g}$ for $1 \mathrm{~min}$ in a swing-out rotor) with DMEM lacking D-glucose and containing $20 \mathrm{mM}$ HEPES, $2 \%$ FCS, 1\% BSA, $50 \mathrm{U} / \mathrm{ml}$ penicillin, $10 \mathrm{mg} / \mathrm{ml}$ streptomycin, and then 2 times with HBSS according to Traxinger and Marshall (29). The suspension was adjusted to a final titer of $1 \times 10^{5}$ cells/ $\mathrm{ml}$. 
Primary culture. Isolated rat adipocytes were maintained in primary culture according to published procedures $(29,30)$ with modifications. Briefly, $10 \mathrm{ml}$ of adipocyte suspension $\left(1 \times 10^{5}\right.$ cells $\left./ \mathrm{ml}\right)$ were incubated at $37^{\circ} \mathrm{C}$ in sterile $50-\mathrm{ml}$ polystyrene tubes in HBSS containing either $5 \mathrm{mM}$ glucose (glucose medium), 20 $\mathrm{mM}$ glucose plus $16 \mathrm{mM}$ glutamine plus $10 \mathrm{nM}$ insulin (glucose/glutamine/insulin medium), $20 \mathrm{mM}$ glucose plus $16 \mathrm{mM}$ glutamine plus $20 \mu \mathrm{M}$ glimepiride (glucose/ glutamine/glimiperide medium), or various combinations thereof for different periods of time as indicated in the figure legends. Subsequently, the cells were washed 4 times with $50 \mathrm{ml}$ each of HBSS lacking glucose, glutamine, and insulin. After the last wash, the cells were suspended in $2.5 \mathrm{ml}$ of the same medium (final titer $4 \times 10^{5}$ cells $/ \mathrm{ml}$ ) and further incubated for $30 \mathrm{~min}$ at $37^{\circ} \mathrm{C}$. This procedure causes the almost complete deactivation of the adipocyte glucose transport system, which had been stimulated by insulin during the primary culture, to basal values (as demonstrated by almost identical basal glucose transport activities of cells that have been incubated for $20 \mathrm{~h}$ with glucose medium, glucose/ glutamine/insulin medium, and glucose/glutamine/glimiperide medium [Fig. 1]). Each of the different adipocyte populations were subjected to the same washing, flotation, and deactivation procedures. Therefore, any reductions of the cell titer and viability were comparable between adipocytes incubated in the different media.

Labeling of adipocytes with ${ }^{32} \mathrm{Pi}$ and $\left[{ }^{35} \mathrm{~S}\right]$ methionine. For incubation with ${ }^{32} \mathrm{Pi}$, the isolated adipocytes were suspended in low Pi medium (20 ml per gram of original tissue) composed of $1 \%(\mathrm{wt} / \mathrm{vol}) \mathrm{BSA}$ in HBSS containing $0.1 \mathrm{mM}$ sodium phosphate $(\mathrm{pH} 7.4)$. Cells $(20-\mathrm{ml}$ aliquots, $1-1.5 \times 10^{6}$ cells $/ \mathrm{ml}$ ) were incubated with ${ }^{32} \mathrm{P}(4$ $\mathrm{mCi}$ per aliquot) for $2 \mathrm{~h}$ at $37^{\circ} \mathrm{C}$ to achieve steady-state labeling with [ $\left.{ }^{32} \mathrm{P}\right]$ orthophosphate before incubation with insulin or glimepiride. For incubation with ${ }^{35}$ S]methionine, adipocytes $\left(50-\mathrm{ml}\right.$ aliquots, $0.5-0.75 \times 10^{6} \mathrm{cells} /$ $\mathrm{ml})$ were incubated with $\left[{ }^{35} \mathrm{~S}\right]$ methionine $(0.5 \mathrm{mCi}$ per aliquot) for $2 \mathrm{~h}$ at $37^{\circ} \mathrm{C}$, subsequently washed twice with HBSS and suspended in HBSS containing $10 \mathrm{mM}$ unlabeled methionine before incubation with insulin or glimepiride. After the end of the incubation, the cells were centrifuged (1000 $\mathrm{g}, 30 \mathrm{~s})$ and the medium aspirated. The cells were rinsed in HBSS containing protease and phosphatase inhibitors (see below) and finally homogenized at $4^{\circ} \mathrm{C}$ in $20 \mathrm{mM}$ Tris/ $\mathrm{HCl}(\mathrm{pH} 7.4), 1 \mathrm{mM}$ EDTA, 250 $\mathrm{mM}$ sucrose containing $100 \mathrm{mM} \mathrm{NaF}, 100 \mu \mathrm{M}$ sodium orthovanadate, $100 \mathrm{mM}$ sodium pyrophosphate, $200 \mu \mathrm{M}$ PMSF, $100 \mu \mathrm{M}$ benzamidine, $20 \mu \mathrm{g} / \mathrm{ml}$ of leupeptin, pepstatin, aprotinin, and antipain each (buffer $A$ ). The cell homogenates were used for subcellular fractionation.

Subcellular fractionation (according to published procedures $[31,32]$ with modifications). Briefly, cells from 12 rats were preincubated in HBSS containing different combinations of glucose, glutamine, insulin, and glimepiride, as indicated in the figure legends, and washed 3 times. After the last washing step, the packed adipocytes $(2 \mathrm{ml})$ were diluted with $50 \mathrm{ml}$ of buffer $A$ and homogenized 10 times in a Teflon-in-glass homogenizer. The cell homogenate was centrifuged $(1500 \mathrm{~g}, 5 \mathrm{~min}$,
Insulin Stimulation

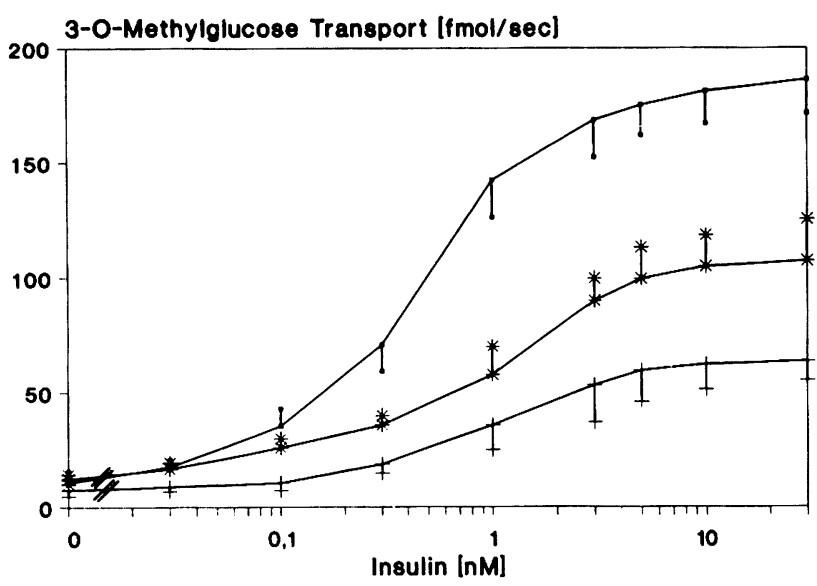

Glimepiride Stimulation

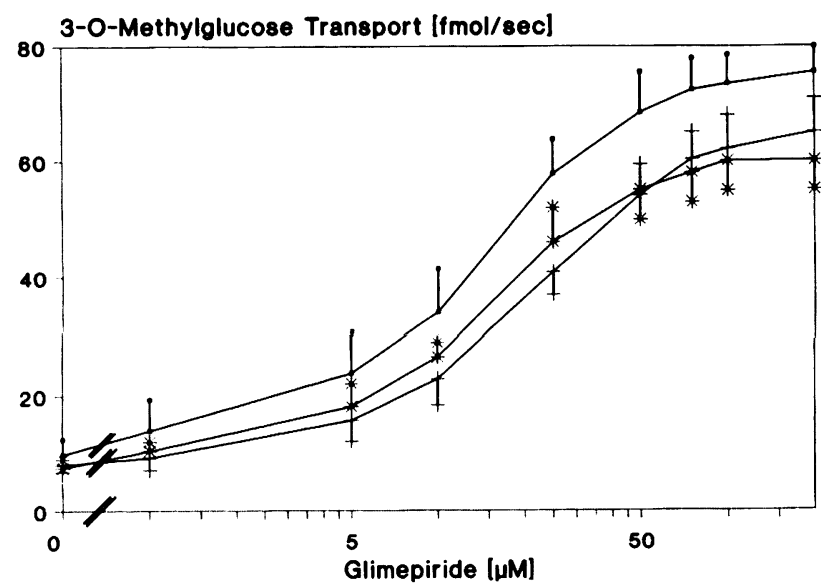

FIG. 1. Stimulation of glucose transport by insulin and glimepiride in normal and insulin-resistant adipocytes. Adipocytes were cultured in glucose medium ( $(\square)$, glucose/glutamine/insulin medium $(+)$, or glucose/glutamine/glimepiride medium (*) for $20 \mathrm{~h}$ at $37^{\circ} \mathrm{C}$. After full deactivation of the glucose transport system, the cells were incubated with various concentrations of insulin or glimepiride for $20 \mathrm{~min}$ at $37^{\circ} \mathrm{C}$ and assayed for 3-O-methylglucose transport. Each value represents the mean \pm SE of 15 measurements with five different cell preparations. For simplification of the data presentation for this and the following experiments, only one half of the error bar ( \pm SE) is shown. The lines indicate the extreme of the SE in elther of the two directions calculated for each value.

$20^{\circ} \mathrm{C}$ ). The postnuclear supernatant was separated from the fat cake, and the pellet fraction (containing adipocyte ghosts and cell debris) with a needle.

For preparation of the total membrane fraction, the postnuclear supernatant was centrifuged $(250,000 \mathrm{~g}, 90$ min, $4^{\circ} \mathrm{C}$ ). The pellet was suspended in $50 \mathrm{ml}$ buffer $A$, recentrifuged, and finally suspended in buffer $A$ at $0.5 \mathrm{mg}$ protein $/ \mathrm{ml}$.

For preparation of LDM, the postnuclear supernatant was sequentially centrifuged $(12,000 \mathrm{~g}, 15 \mathrm{~min} ; 50,000 \mathrm{~g}$, $30 \mathrm{~min} ; 250,000 \mathrm{~g}, 90 \mathrm{~min})$. The pellet of the last centrifugation was suspended in buffer $A$, recentrifuged, and finally suspended in buffer $A$ at $1 \mathrm{mg}$ protein $/ \mathrm{ml}$.

For preparation of $\mathrm{PM}$, the pellet of the $12,000 \mathrm{~g}$ centrifugation was suspended in $35 \mathrm{ml}$ of buffer $A$ and 
recentrifuged (1000 $\mathrm{g}, 10 \mathrm{~min})$. The supernatant was centrifuged $(12,000 \mathrm{~g}, 20 \mathrm{~min})$. The pellet was washed once, suspended in $5 \mathrm{ml}$ of buffer $\mathrm{A}$, layered onto a $20-\mathrm{ml}$ cushion of $38 \%(w t / v o l)$ sucrose, $20 \mathrm{mM}$ Tris/ $/ \mathrm{HCl}(\mathrm{pH}$ 7.4), $1 \mathrm{mM}$ EDTA, and centrifuged $(110,000 \mathrm{~g}, 60 \mathrm{~min}$, $\left.4^{\circ} \mathrm{C}\right)$. The membranes at the interface between the two layers $(1 \mathrm{ml})$ were removed by suction, diluted with three volumes of buffer $A$, and layered on top of an $8-\mathrm{ml}$ cushion of $28 \%$ Percoll, $250 \mathrm{mM}$ sucrose, $20 \mathrm{mM}$ Tris/ $\mathrm{HCl}$ $(\mathrm{pH} 7), 1 \mathrm{mM}$ EDTA. Aiter centrifugation $(45,000 \mathrm{~g}, 30$ min, $4^{\circ} \mathrm{C}$ ), the PMs were withdrawn from the lower third of the gradient $(1 \mathrm{ml})$ with a Pasteur pipet, diluted with 10 - Jlumes of buffer $A$, and recentrifgued $(250,000 \mathrm{~g}, 90$ $\min , 4^{\circ} \mathrm{C}$ ). The pellet was suspended, recentrifuged, and finally dissolved in buffer $A$ at $0.5 \mathrm{mg}$ protein $/ \mathrm{ml}$. All samples were stored at $-80^{\circ} \mathrm{C}$.

Control experiments were performed using 5 '-nucleotidase and lipoprotein lipase activity as PM markers and rotenone-insensitive cytochrome $c$ reductase and glucose-6-phosphatase as microsomal markers (microsomes derived from endoplasmic reticulum and Golgi stacks cofractionate with LDM). They demonstrated that the observed alterations in GLUT distribution between PMs and LDMs after primary culture with glucose medium, glucose/glutamine/insulin medium, glucose/glutamine/glimepiride medium, or short-term treatment with insulin or glimepiride are not attributable to different recoveries of PM and microsomal membrane protein or variations in cross contamination of the membrane fractions isolated from the differently treated cells (data not shown).

Assay for glucose transport. Basal, insulin-, and glimepiride-stimulated transport of glucose was measured after incubation of $200 \mu \mathrm{l}$ of adipocytes in HBSS $\left(4 \times 10^{5}\right.$ cells $/ \mathrm{ml}$ ) with different concentrations of insulin and glimepiride, respectively, (complete dose-response curves) in $15-\mathrm{ml}$ polystyrene tubes for $20 \mathrm{~min}$ at $37^{\circ} \mathrm{C}$. Initial rates of glucose transport were determined by addition of $50 \mu \mathrm{l}$ HBSS containing either $100 \mu \mathrm{M}$ 2-deoxy-D-[1- $\left.{ }^{14} \mathrm{C}\right]$ glucose $(0.5 \mu \mathrm{Ci})$ or $100 \mu \mathrm{M}$ 3-O-methyl-o-[1-14 C]glucose $(0.2 \mu \mathrm{Ci})$. After 5 -min (deoxyglucose) or 30-s (methylglucose) incubation at room temperature, the reaction was stopped by addition of cytochalasin $B$ (final concentration $50 \mu \mathrm{M}$ ) and immediate separation of the cells $(200-\mu l$ aliquots) from the medium by centrifugation through $150 \mu \mathrm{l}$ of dinonylphthalate oil in plastic tubes. The tubes were then cut through the oil layer and the adipocytes counted for radioactivity in $10 \mathrm{ml}$ of scintillation cocktail ACSII. Glucose uptake by diffusion and trapping of glucose in the intercellular spaces of the packed adipocytes were corrected by performing control incubations in which cytochalasin B was present before addition of the labeled glucose. These radioactivity values were subtracted from the total cell-associated radioactivity.

It has been demonstrated previously $(33,34)$ that the initial rates of glucose transport can be accurately determined with both hexose derivatives, thus yielding comparable stimulatory factors of deoxyglucose and methylglucose transport by insulin. Nevertheless, the key findings (alterations of the dose-response curves for insulin and glimepiride after primary culture of adipocytes) obtained with 2-deoxyglucose were confirmed with 3-O-methylglucose (Fig. 1). The use of this glucose derivative excludes any influence of the subsequent hexokinase reaction on the transport kinetics. Transport of 3-O-methylglucose was assayed over $30 \mathrm{~s}$ and thus led to underestimation of the $V_{\max }$ and $\mathrm{ED}_{50}$ values for insulin-stimulated transport. Nevertheless, the differences in the initial transport velocities between 2-deoxyglucose and 3-O-methylglucose are rather small, and the stimulatory factors for insulin are close to published values (34). Moreover, underestimations for glucose transport stimulation by glimepiride would not affect the main conclusions of this study.

Calculations of sensitivity and responsiveness toward insulin and glimepiride were performed by running complete dose-response curves for insulin $(0.03-30 \mathrm{nM})$ and glimepiride $(1-200 \mu \mathrm{M})$. Maximal insulin and glimepiride stimulation of glucose transport $\left(V_{\max }\right)$ was determined at $10 \mathrm{nM}$ and $50 \mu \mathrm{M}$, respectively. A decrease of $V_{\max }$ with no change in the sensitivity toward the corresponding compound is defined as decreased responsiveness. An increase in the concentrations of insulin and glimepiride necessary for $\mathrm{ED}_{50}$ of glucose transport with no change in the maximal responsiveness is defined as decreased sensitivity of the glucose transport system toward insulin and glimepiride. In this study, the terms insulin-resistant and desensitized adipocytes are used for cells that after primary culture display reduced insulin responsiveness or sensitivity or both.

Western blotting of GLUT1 and GLUT4. Proteins were precipitated with $5 \%$ TCA (30 min on ice, 10,000 g, 5 min; followed by three acetone washes and evaporation), dissolved in Laemmli buffer containing 2\% mercaptoethanol, heated $\left(95^{\circ} \mathrm{C}, 5 \mathrm{~min}\right)$, separated by SDS-PAGE, and transferred electrophoretically to nitrocellulose sheets (35). The blots were saturated for $4 \mathrm{~h}$ at room temperature with PBS containing $5 \%$ defatted milk powder. After addition of anti-GLUT1 (1:200) or anti-GLUT4 (1:1000) antiserum, the incubation was continued for $16 \mathrm{~h}$ at $4^{\circ} \mathrm{C}$. Subsequently, the sheets were washed 4 times $(30 \mathrm{~min}$ each) in PBS containing $1 \%$ TX-100 and then incubated with $\left[{ }^{125} \mathrm{l}\right]$ protein $\mathrm{A}(0.5 \mu \mathrm{Ci} / \mathrm{ml})$ in PBS containing $5 \%$ milk powder. After four washes (see above), the blots were dried and subjected to autoradiography. Immunoreactivity was quantitated by cutting rectangular strips, corresponding to the locations of either GLUT1 or GLUT4 on the developed films, from the nitrocellulose filters and counting the filter strips in a $\gamma$-counter. Specific binding was determined after subtracting half of the sum of background radioactivities present on size-matched strips of the filter cut from an area above and below each immunoreactive transporter band.

Immunoprecipitation of radiolabeled GLUT4. PMS, LDMs, and cell homogenates from ${ }^{32} \mathrm{Pi}$ - or $\left.{ }^{35} \mathrm{~S}\right]$ methionine-labeled adipocytes were solubilized in Laemmli buffer $\left(5 \mathrm{~min}, 95^{\circ} \mathrm{C}\right)$ at $0.5 \mathrm{mg}$ protein per $\mathrm{ml}$. Equivalent sample volumes (up to $50 \mu \mathrm{l}$ ) were diluted with $1 \mathrm{ml}$ of buffer $A$ containing $1 \%$ TX-100, $150 \mathrm{mM} \mathrm{NaCl}$ and protease and phosphatase inhibitors, and centrifuged $(10,000 \mathrm{~g}, 5 \mathrm{~min})$. The supernatant was incubated with 50 
$\mu$ l of anti-rat GLUT4 peptide antibodies that had been adsorbed to protein A-Sepharose $(10 \mu \mathrm{l}$ of a $1: 500$ antiserum dilution was incubated with $50 \mathrm{mg}$ protein A-Sepharose beads in $0.5 \mathrm{ml}$ of the buffer described above for $2 \mathrm{~h}$ at $4^{\circ} \mathrm{C}$ under constant shaking. The beads were pelleted by centrifugation, washed twice with buffer, and resuspended in $1 \mathrm{ml}$ of buffer). After $1 \mathrm{~h}$ at $4^{\circ} \mathrm{C}$ under constant shaking, the beads were collected by centrifugation $(10,000 \mathrm{~g}, 30 \mathrm{~s})$, washed sequentially with $1 \mathrm{ml}$ each of buffer $A$ containing $1 \%$ TX-100/100 $\mathrm{mM} \mathrm{NaCl}$ and $0.1 \% \mathrm{TX}-100 / 50 \mathrm{mM} \mathrm{NaCl}$ and $0.1 \% \mathrm{TX}-100$. The final pellet with the immunocomplex-containing beads was solubilized in $50 \mu \mathrm{l}$ of sample buffer $\left(5 \mathrm{~min}, 95^{\circ} \mathrm{C}\right)$ and centrifuged. The supernatant was analyzed by SDSPAGE and fluorography.

Miscellaneous procedures. Western blotting with rabbit anti- $\beta$-COP, anti-Na ${ }^{+}-\mathrm{K}^{+}$-ATPase, and anti-GLUT4 (total protein) antibodies was performed as described above for anti-GLUT4 peptide antibodies but using 1:500, 1:150, and 1:250 antiserum dilutions, respectively. This was followed by decoration of the washed nitrocellulose filters with anti-rabbit $\left[{ }^{125} \mathrm{l}\right] \mathrm{lgG}(0.2 \mu \mathrm{Ci} / \mathrm{ml})$ and autoradiography for $\beta$-COP (36) and $\mathrm{Na}^{+}-\mathrm{K}^{+}$-ATPase (37), and with anti-rabbit IgG coupled to alkaline phosphatase and chemiluminescence assay for GLUT4. SDS-PAGE using $5 \%$ stacking and $15 \%$ running gels $(38,39)$, autoradiography using Kodak X-OMAT AR films, protein determination with the amidoblack staining method (40), and assays for $5^{\prime}$-nucleotidase, lipoprotein lipase (41), rotenone-insensitive cytochrome $c$ reductase, and glucose6 -phosphatase $(31,42)$ were performed according to published procedures.

\section{RESULTS}

Primary culture of rat adipocytes can induce insulin resistance of glucose transport. As Marshall et al. $(21,29)$ demonstrated previously and as is confirmed in this study, primary culture of isolated rat adipocytes in the presence of high concentrations of glucose and insulin leads to a marked desensitization of the glucose transport system. In cells incubated for $20 \mathrm{~h}$ in the presence of $20 \mathrm{mM}$ glucose, $16 \mathrm{mM}$ glutamine, and 10 $\mathrm{nM}$ insulin (hereafter called insulin-resistant or desensitized cells), both the insulin sensitivity (Fig. $1 A: E_{50}$ for insulin $1.85 \mathrm{nM}$ in insulin-resistant cells vs. $0.45 \mathrm{nM}$ in normal cells) and maximal insulin responsiveness (Fig. 1A: $61 \mathrm{fmol} / \mathrm{s}$ in insulin-resistant cells vs. $186 \mathrm{fmol} / \mathrm{s}$ in normal cells) of 3-O-methylglucose transport are decreased compared with cells maintained at $5 \mathrm{mM}$ glucose during the same period of time (hereafter called normal cells).

Glimepiride stimulates glucose transport in normal and desensitized adipocytes. The sulfonylurea drug, glimepiride, stimulates initial 3-O-methylglucose transport velocity in normal rat adipocytes (Fig. 1B) in a concentration-dependent manner $\left(\mathrm{ED}_{50}=16.5 \mu \mathrm{M}\right)$ up to eightfold $(75 \mathrm{fmol} / \mathrm{s})$. This comprises $-50 \%$ of the maximal insulin stimulation. With insulin-resistant cells, the dose-response curve for glimepiride stimulation of glucose transport is only slightly shifted to the right
Insulin Sensitivity

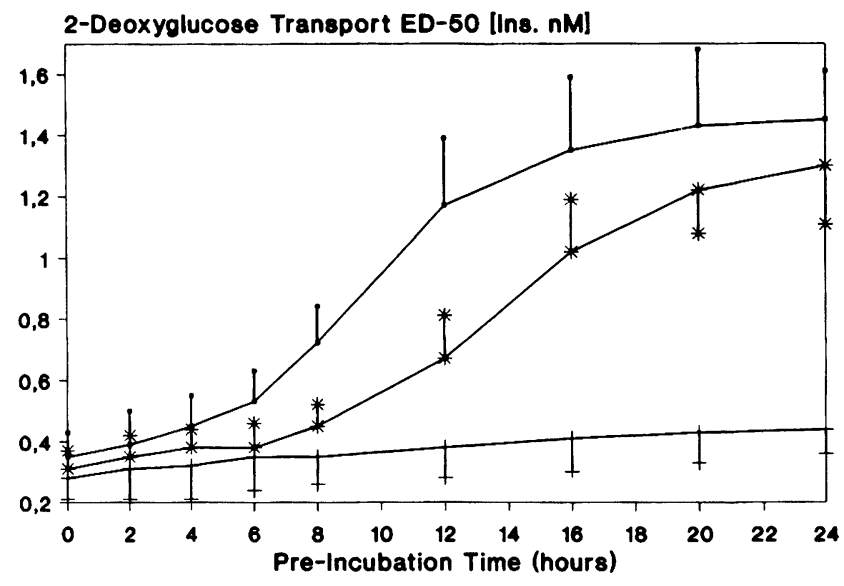

Glimepiride Sensitivity

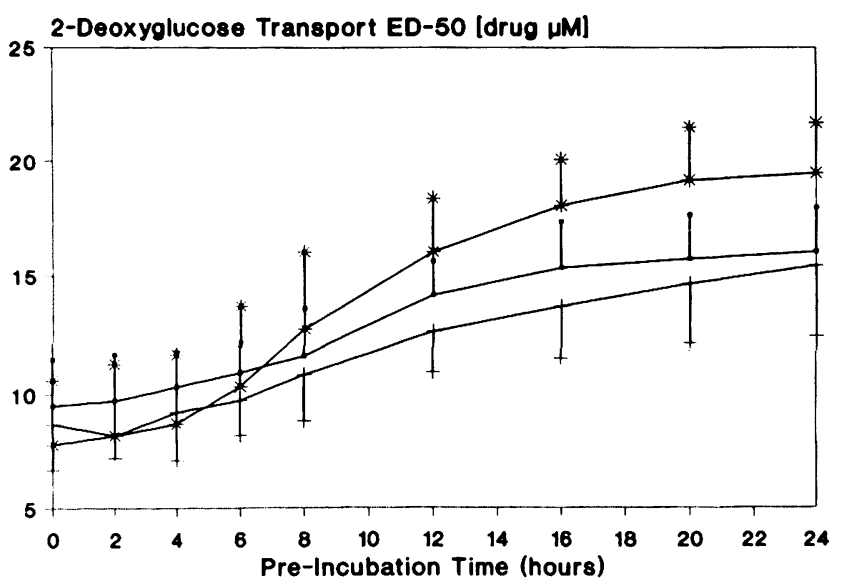

FIG. 2. Time course of the loss of insulin and glimepiride sensitivity of glucose transport. Adipocytes were cultured in glucose medium $(+)$, glucose/glutamine/insulin medium ( $\square$ ), or glucose/glutamine/ glimepiride medium $\left(^{*}\right)$ for various periods of time at $37^{\circ} \mathrm{C}$. After full deactivation of the glucose transport system, the cells were incubated with a full range of insulin $(1-30 \mathrm{nM})$ or glimepiride concentrations $(1-200 \mu \mathrm{M})$ for $20 \mathrm{~min}$ at $37^{\circ} \mathrm{C}$ and assayed for 2-deoxyglucose transport. Insulin and glimepiride sensitivity $\left(E^{50}\right)$ of the glucose transport system was calculated at the indicated times from the insulin and glimepiride dose-response curves for each of the three adipocyte populations. Each value represents the mean \pm SE of 16 measurements with four different cell preparations.

$\left(E D_{50}=22.5\right.$ vs. $\left.16.5 \mu \mathrm{M}\right)$ with a concomitant $15 \%$ decrease of the maximal transport velocity.

The extent of resistance toward insulin or glimepiride is dependent on the duration of the primary culture and insulin concentration (Figs. 2-4). The development of reduced insulin responsiveness of 2-deoxyglucose transport (Fig. 3A; onset after $2 \mathrm{~h}$ ) precedes the appearance of decreased insulin sensitivity (Fig. $2 A$; onset after $6 \mathrm{~h})$. After $20 \mathrm{~h}$ incubation, both parameters are altered most pronouncedly. Similar data were obtained with 3-O-methylglucose (compare with Fig. 1A). Primary culture with $5-100 \mathrm{nM}$ causes a significant reduction of the insulin responsiveness of 3-O-methylglucose transport (Fig. $4 A_{;} \mathrm{ED}_{50}=4.5 \mathrm{nM}$ for half-maximal loss of responsiveness). The maximal effect requires $50 \mathrm{nM}$ insulin. Therefore, $20 \mathrm{~h}$ primary culture in the presence of $50 \mathrm{nM}$ 
Insulin Responsiveness

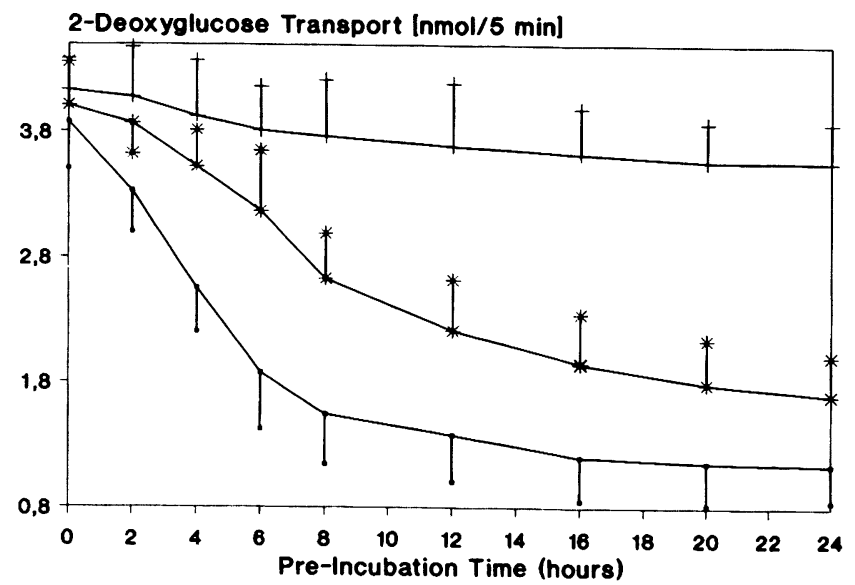

Glimepiride Responsiveness

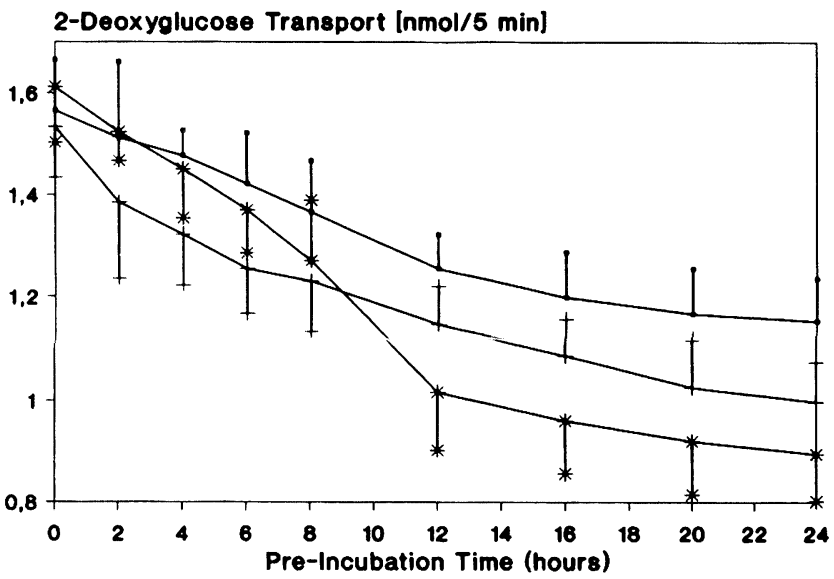

FIG. 3. Time course of the loss of insulin and glimepirlde responsiveness of glucose transport. Adipocytes were cultured in glucose medium (+), glucose/glutamine/insulin medium (D), or glucose/glutamine/glimepiride medium $(*)$ for various periods of time. After full deactivation of the glucose transport system, the cells were incubated with $10 \mathrm{nM}$ insulin or $20 \mu \mathrm{M}$ glimepiride for $20 \mathrm{~min}$ at $37^{\circ} \mathrm{C}$ and subsequently assayed for 2-deoxyglucose transport. Each value represents the mean \pm SE of 15 measurements with five different cell preparations.

insulin were chosen for all subsequent experiments. In contrast, there is no significant loss of glimepiride responsiveness (Figs. $3 B$ and $4 A$ ) and sensitivity (Fig. 2B) during primary culture (Figs. $2 B$ and $3 B$ ) with any insulin concentration (Fig. $4 A$ ) if one takes into account the general loss of glucose transport stimulation by insulin or glimepiride during the incubation period.

Glimepiride can substitute for insulin in desensitizing glucose transport in primary cultured adipocytes. It has been suggested that the requirement of insulin for desensitization of isolated rat adipocytes by high concentrations of glucose, glutamine, and insulin is based solely on the increased influx of glucose (21). Because glimepiride stimulates glucose transport to about halfmaximal insulin levels, we asked whether this sulfonylurea drug also causes insulin resistance of glucose transport when present during primary culture. Figure $1 A$ shows that glimepiride causes a marked reduction of the
Insulin and Glimepiride Responsiveness

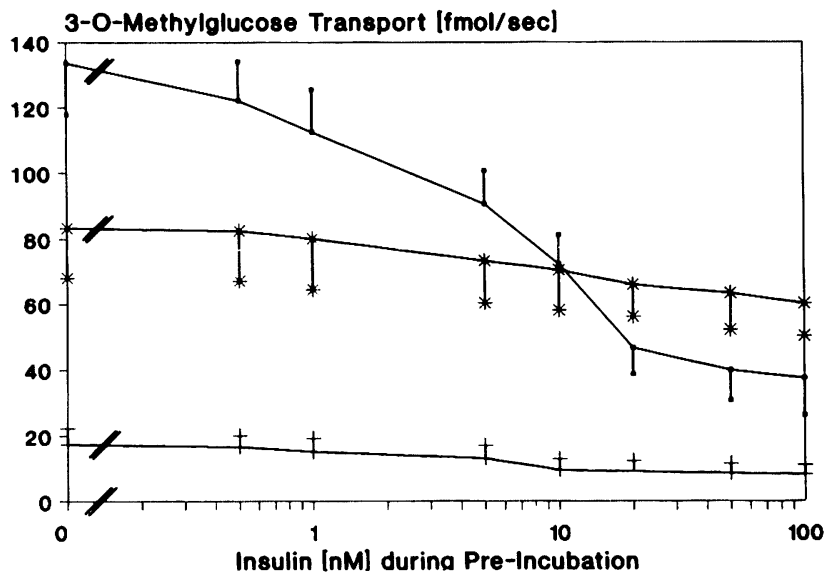

Insulin and Glimepiride Responsiveness

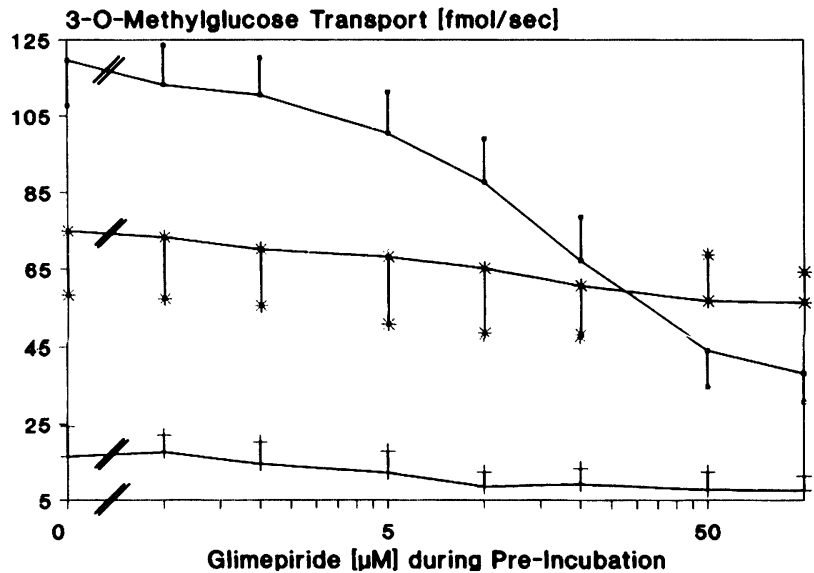

FIG. 4. Dependency of the insulin and glimepiride responsiveness of glucose transport on the insulin and glimepiride concentration during long-term incubation. Adipocytes were cultured in medium containing $20 \mathrm{mM}$ glucose plus $16 \mathrm{mM}$ glutamine plus various concentrations of insulin or glimepiride for $20 \mathrm{~h}$ at $37^{\circ} \mathrm{C}$. After full deactivation of the glucose transport system, one portion of the cells was incubated directly in the absence $(+)$ or presence of $1.85 \mathrm{nM}$ insulin $(\square)$ or $20 \mu \mathrm{M}$ glimepiride $\left(^{*}\right)$ for $20 \mathrm{~min}$ at $37^{\circ} \mathrm{C}$ and assayed for 3-0-methylglucose transport. Each value represents the mean \pm SE of six measurements with two different cell preparations.

maximal insulin-stimulated 3-O-methylglucose transport velocity (102 fmol/s in insulin-resistant cells vs. $192 \mathrm{fmol} / \mathrm{s}$ in normal cells) and an increase of the $\mathrm{ED}_{50}$ for insulin (1.1 $\mathrm{nM}$ in insulin-resistant cells vs. $0.45 \mathrm{nM}$ in normal cells). The most pronounced reductions of insulin responsiveness and sensitivity become evident after incubation for $20 \mathrm{~h}$ (Figs. $2 A$ and $3 A$ ). The time course for the glimepiride-induced insulin resistance lags $-2-4 \mathrm{~h}$ behind the insulin effect in both its onset and time to reach maximum. Interestingly, as insulin present during primary culture causes desensitization of the glucose transport toward insulin but not glimepiride, long-term treatment with this drug provokes insulin resistance of 3-O-methylglucose transport but only marginally impairs transport stimulation by the drug itself (Fig. 1B). The detailed analysis revealed that glimepiride causes an $\sim 50 \%$ reduction of the maximal insulin-stimulated 2-deoxyglu- 
TABLE 1

Effect of glimepiride on the induction of insulin resistance of glucose transport

\section{3-O-methylglucose transport}

\begin{tabular}{|c|c|c|c|c|}
\hline \multicolumn{2}{|c|}{ Percentage of maximal response } & \multicolumn{2}{|c|}{ Percentage increase of $E D_{50}$} & \multirow{2}{*}{$\begin{array}{c}\text { Conditions of } \\
\text { primary } \\
\text { culture }\end{array}$} \\
\hline Insulin & Glimepiride & Insulin & Glimepiride & \\
\hline $\begin{array}{l}55.7 \pm 6.5 \\
32.9 \pm 5.5 \\
31.2 \pm 4.1\end{array}$ & $\begin{array}{l}89.4 \pm 9.9 \\
83.1 \pm 7.8 \\
74.3 \pm 6.1\end{array}$ & $\begin{array}{l}252 \pm 20.3 \\
291 \pm 26.7 \\
314 \pm 35.7\end{array}$ & $\begin{array}{l}110 \pm 13.4 \\
141 \pm 10.2 \\
149 \pm 16.1\end{array}$ & $\begin{array}{l}\text { Glc/Gln/Gli } \\
\text { Glc/Gln/Ins } \\
\text { Glc/Gln/Ins/Gli }\end{array}$ \\
\hline
\end{tabular}

Data are means \pm SE of six measurements with different cell preparations. Adipocytes were cultured in glucose/glutamine/ glimepiride medium or glucose/glutamine/insulin medium in the absence or presence of $50 \mu \mathrm{M}$ glimepiride (glucose/glutamine/ insulin/glimepiride) for $20 \mathrm{~h}$ at $37^{\circ} \mathrm{C}$. After full deactivation of the glucose transport system, portions of the cells were incubated with a full range of concentrations of either insulin $(0.02-30 \mathrm{nM})$ or glimepiride $(1-200 \mu \mathrm{M})$ for 20 min at $37^{\circ} \mathrm{C}$ and then assayed for 3-O-methylglucose transport. The maximal initial transport velocities ( $30 \mathrm{nM}$ insulin or $50 \mu \mathrm{M}$ glimepiride, respectively) and the increments of the $\mathrm{ED}_{50}$ values for insulin and glimepiride were calculated for each population of adipocytes as the percentage of the corresponding values for cells kept in glucose medium (set at 100\%). Glc, glucose; Gln, glutamine; Ins, insulin; Gli, glimepiride.

cose transport (Fig. $3 A$ ) and a 2.9 -fold increase of the $E D_{50}$ for insulin (Fig. $2 A$ ). The maximal glimepiridestimulated glucose transport (Fig. $3 B$ ) and the $E_{50}$ values for glimepiride (Fig. 2B) showed only a very slight decrease and increase, respectively, after various periods of primary culture with glimepiride. Figure $4 B$ shows the dependency of the glimepiride-induced insulin resistance on the drug concentration. The concentration required for half-maximal inhibition is $13.5 \mu \mathrm{M}$ and thus closely correlated to the $E D_{50}$ value for stimulation of glucose transport by glimepiride.

In accordance with the impairment of the insulinstimulated glucose transport by long-term insulin and glimepiride treatment, the drug does not antagonize the desensitization of the glucose transport system toward insulin when present during the primary culture together with insulin (Table 1). The maximal glucose transport velocity, responsiveness, and $\mathrm{ED}_{50}$ values for insulin do not differ significantly between insulin-resistant adipocytes cultured in the absence or presence of glimepiride. Glimepiride stimulates translocation of GLUT1 and GLUT4. Next we were interested in the mechanism of glucose transport stimulation by glimepiride in normal and insulin-resistant adipocytes and of insulin resistance induced by long-term glimepiride treatment. Drug stimulation of glucose transport may be attributable to recruitment of GLUT molecules from LDMs to PMs as has been well established for insulin $(43,44)$ and to increased synthesis of GLUT. Therefore, we studied whether glimepiride mimicks the insulin-stimulated increase of cell surface expression of GLUT1 and GLUT4 (45). For studying the translocation of GLUT1 and GLUT4, cultured rat adipocytes were treated with insulin or glimepiride and then fractionated into LDMs and PMs. Their relative purity is proved by the enrichment and little mutual crosscontamination of typical marker proteins for PMs, i.e., lipoprotein lipase, $5^{\prime}$-nucleotidase, $\mathrm{Na}^{+}-\mathrm{K}^{+}$-ATPase $(\alpha-$ subunit), and for microsomes (which cofractionate but are not identical with LDM), i.e., glucose-6-phosphatase, rotenone-insensitive cytochrome $c$ reductase, and $\beta$-COP, as revealed by enzymic assays (data not shown) and Western blot analysis (Table 2). The latter demonstrates $\sim 10 / 5$-fold enrichment of $\mathrm{Na}^{+}-\mathrm{K}^{+}$-ATPase/
$\beta-C O P$ in the PM and LDM fractions, respectively, and vice versa. PM and LDM contain only $2-4 \%$ of the total $\beta$-COP and $\mathrm{Na}^{+}-\mathrm{K}^{+}$-ATPase protein, respectively. The number of GLUT molecules in both membrane fractions was assessed by Western blotting with specific antiGLUT1 and anti-GLUT4 peptide antisera. For evaluation of possible effects on gene expression of GLUT1 and GLUT4, total cellular membrane fractions, from which PMs and LDMs were ultimately derived, were prepared and tested for anti-GLUT1 and anti-GLUT4 immunoreactivity.

Incubation of isolated rat adipocytes with insulin increases the amount of GLUT4 and GLUT1 in isolated PM by $\sim 5$ - to 6 -fold and 2-fold, respectively (Fig. $5 A$ and $B$, lanes 3 and 6 ; Fig. $6 A$ and $B$ ). In contrast, the amount of both GLUT isoforms decreases in the LDM fraction (lanes 2 and 5). This reflects the insulin-induced redistribution of GLUT4 and GLUT1 from internal stores to the cell surface. Translocation of GLUT is provoked also by glime-

TABLE 2

Distribution of marker proteins in adipocyte membranes

\begin{tabular}{|c|c|c|c|c|c|}
\hline \multirow[b]{2}{*}{ Fraction } & \multirow{2}{*}{$\begin{array}{l}\text { Total } \\
\text { protein } \\
(\mathrm{mg})\end{array}$} & \multicolumn{2}{|c|}{$\begin{array}{l}\text { Relative immu- } \\
\text { noreactivity } \\
\text { (arbitrary units) }\end{array}$} & \multicolumn{2}{|c|}{$\begin{array}{l}\text { Relative } \\
\text { yield } \\
(\%)\end{array}$} \\
\hline & & $\begin{array}{l}\mathrm{Na}^{+}-\mathrm{K}^{+}- \\
\text {ATPase }\end{array}$ & $\stackrel{\beta-}{C O P}$ & $\begin{array}{l}\mathrm{Na}^{+}-\mathrm{K}^{+}- \\
\text {ATPase }\end{array}$ & $\stackrel{\beta-}{C O P}$ \\
\hline $\begin{array}{l}\text { Total membranes } \\
\text { PM fraction } \\
\text { LDM fraction }\end{array}$ & $\begin{array}{l}8.04 \\
0.39 \\
1.02\end{array}$ & $\begin{array}{l}1 \\
9.65 \\
0.25\end{array}$ & $\begin{array}{l}1 \\
0.76 \\
5.42\end{array}$ & $\begin{array}{r}100 \\
46.8 \\
2.5\end{array}$ & $\begin{array}{r}100 \\
3.6 \\
55.3\end{array}$ \\
\hline
\end{tabular}

Rat adipocytes were fractionated into total membranes, LDM, and PM. One hundred micrograms of protein of each fraction was separated on SDS-PAGE, transferred to nitrocellulose, and immunodecorated with rabbit anti- $\mathrm{Na}^{+}-\mathrm{K}^{+}$-ATPase and anti- $\beta$ COP antibodies. After incubation with $\left[{ }^{125} /\right]$ anti-rabbit IgG, antibodies and autoradiography nitrocellulose strips corresponding to the visualized $\mathrm{Na}^{+}-\mathrm{K}^{+}$-ATPase and $\beta$-COP protein bands were counted for radioactivity in a $\gamma$-counter. Correction for background binding was done as described for Fig. 6 . The radioactivity measured for $100 \mu \mathrm{g}$ total membrane protein was set at 1 arbitrary unit (relative immunoreactivity), and the radioactivity calculated for the total adipocyte membranes was set at $100 \%$ (relative yield). 
A

treatment $C O N$
fraction $T|L| P|T| L|P| T|L| P$

$\frac{1}{0}$

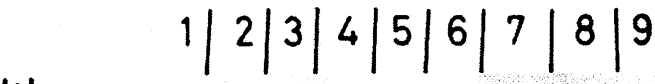

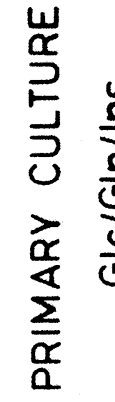

B

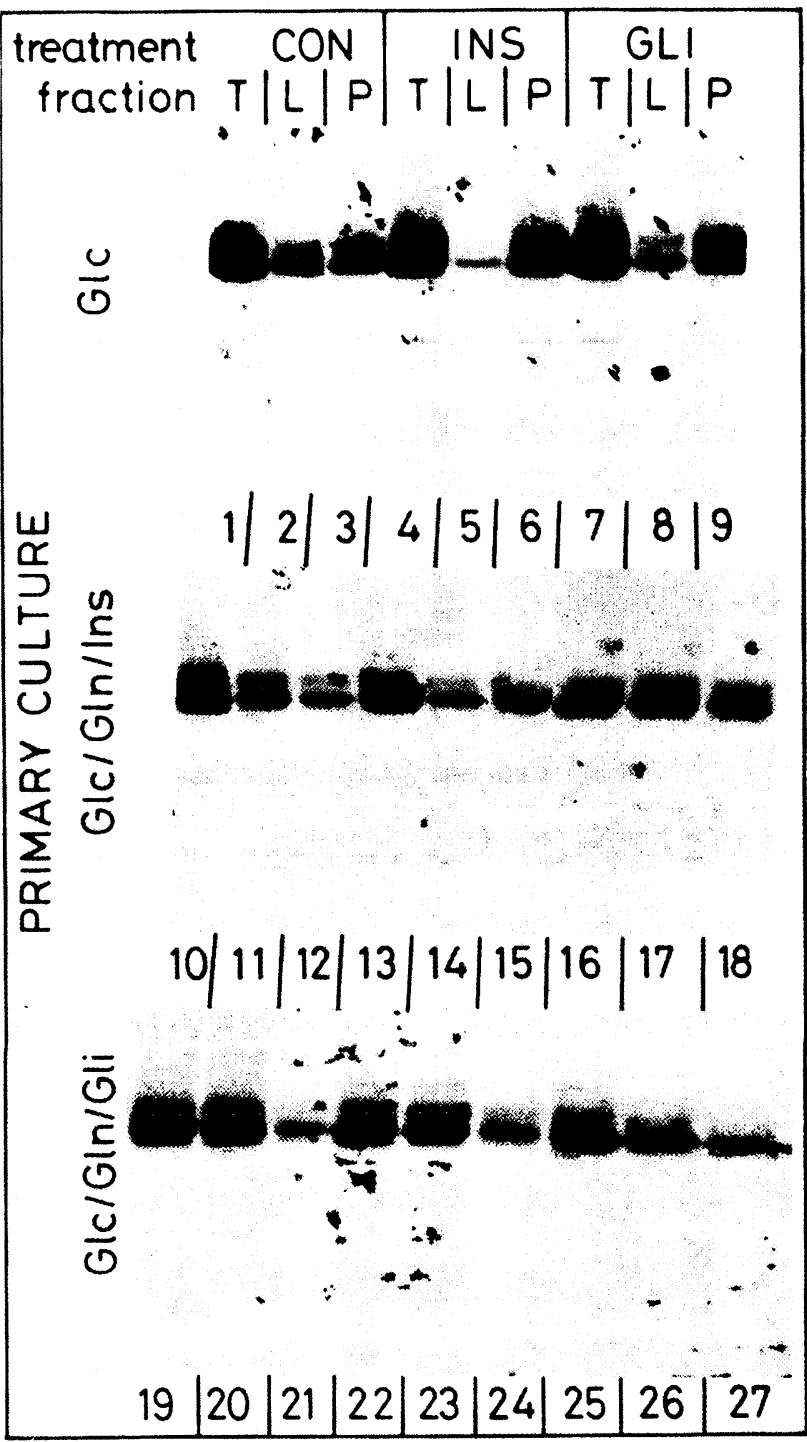

FIG. 5. Effect of primary culture and treatment of adipocytes with insulin and glimepiride on GLUT translocation. Adipocytes were cultured in glucose medium, glucose/glutamine/insulin medium, or glucose/glutamine/glimepiride medium for $20 \mathrm{~h}$ at $37^{\circ} \mathrm{C}$. After full deactivation of the glucose transport system, the cells were incubated in the absence (CON) or presence of $10 \mathrm{nM}$ insulin (INS) or $20 \mu \mathrm{M}$ glimepiride (GL/) for 20 $\mathrm{min}$ at $37^{\circ} \mathrm{C}$. Subsequently, the cells were homogenized. From one half of the homogenate total membranes were prepared $(T)$. The other half was fractionated into LDM $(L)$ and PM $(P)$ as described in METHODs. Equivalent amounts of protein $(T, 200 \mu \mathrm{g} ; \mathrm{L}, 18.4 \mu \mathrm{g} ; P, 20.6 \mu \mathrm{g} ;$ the relative subcellular distribution of the protein content did not differ significantly between the three adipocyte populations and after stimulation with insulin or glimepiride; data not shown) were separated on SDS-PAGE, and the amount of GLUT1 and GLUT4 in each fraction was determined separately by immunoblotting with anti-GLUT1 and anti-GLUT4 antibodies, respectively. Autoradiograms of the immunoblots with anti-GLUT4 (A) and anti-GLUT1 antibody $(B)$ subsequently decorated with $\left[{ }^{125} \mid\right]$ protein $A$ for a typical experiment repeated three times are shown.

piride $(25 \mu \mathrm{M})$ with $\sim 50 \%$ efficiency compared with insulin (Fig. $5 A$ and $B$, lanes 8 and 9 ; Fig. $6 A$ and $B$ ). This explains, at least in part, stimulation of glucose transport by the drug.

Glimepiride-stimulated GLUT translocation is only slightly reduced in desensitized adipocytes. Desensitization of the glucose transport system leads to a markedly impaired insulin-stimulated increase of the GLUT4 and GLUT1 number in the PM and decrease in the LDM fraction (Fig. $5 A$ and $B$, lanes 14, 15, 23, and 24; Fig. $6 C$ and $D$ ). The stimulation factors for GLUT4 and GLUT1 translocation in insulin-resistant versus normal adipocytes, calculated as the ratio of the amount of immunoreactive material (arbitrary units in Fig. 6) in the PM fraction in the stimulated and basal state, were diminshed (2.7 and 2.8 vs. 5.4). In contrast, the stimulation factors of glimepiride are only slightly diminished in insulin-resistant versus normal adipocytes, irrespective of whether the resistance has been induced by insulin (2.6 vs. 3.3) or glimepiride (3.1 vs. 3.3; Fig. $5 A$ and $B$, lanes $17,18,26$, and 27 ; Fig. $6 E$ and $F$ ). This correlates well with the decreased insulin but almost unaltered glimepiride responsiveness and sensitivity of the glucose transport in desensitized adipocytes.

The total number of GLUT4 and GLUT1 determined in a total membrane fraction does not change during shortterm incubation with either insulin or glimepiride (Fig. 5 , lanes 1, 4, and 7; Fig. $6 A$ and $B$ ). In contrast, the amount 
A Responsiveness of Glut4 Translocation

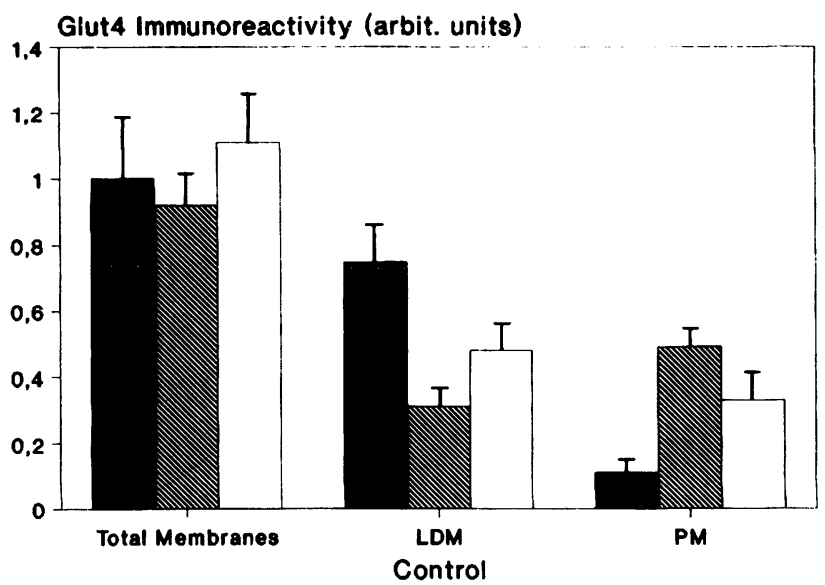

C Responsiveness of Glut4 Translocation

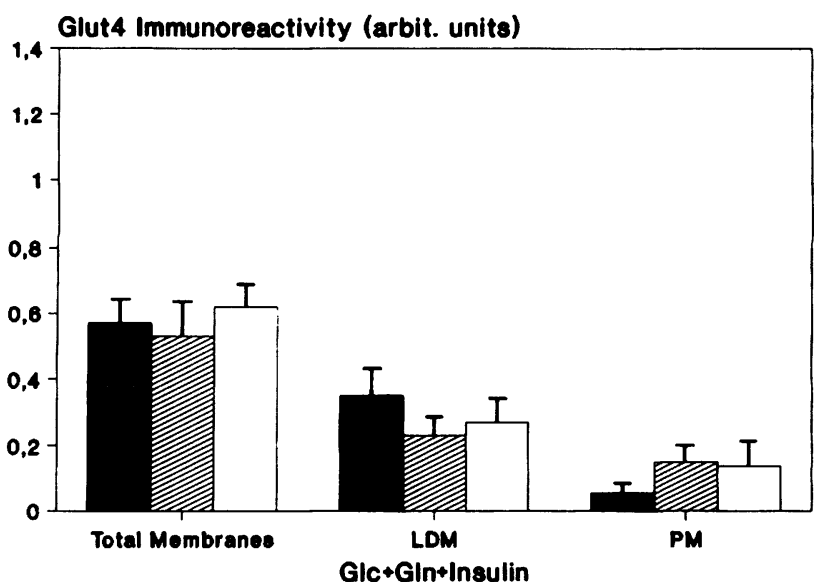

E Responsiveness of Glut4 Translocation

Glut4 Immunoreactivity (arbit. units)

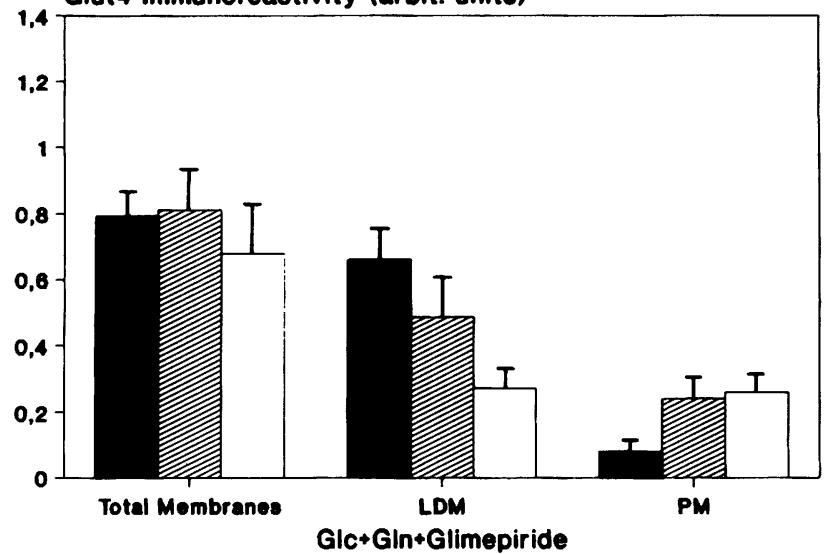

B Responsiveness of Glut1 Translocation

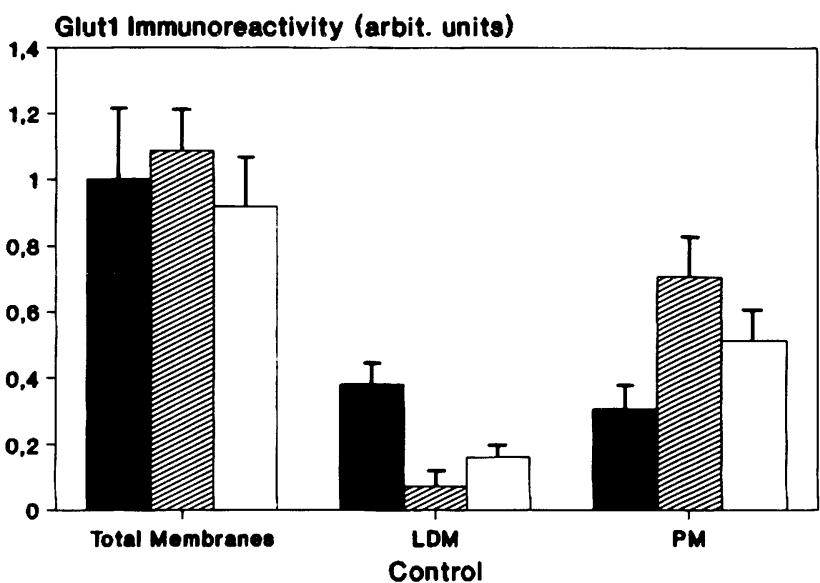

D Responsiveness of Glut1 Translocation

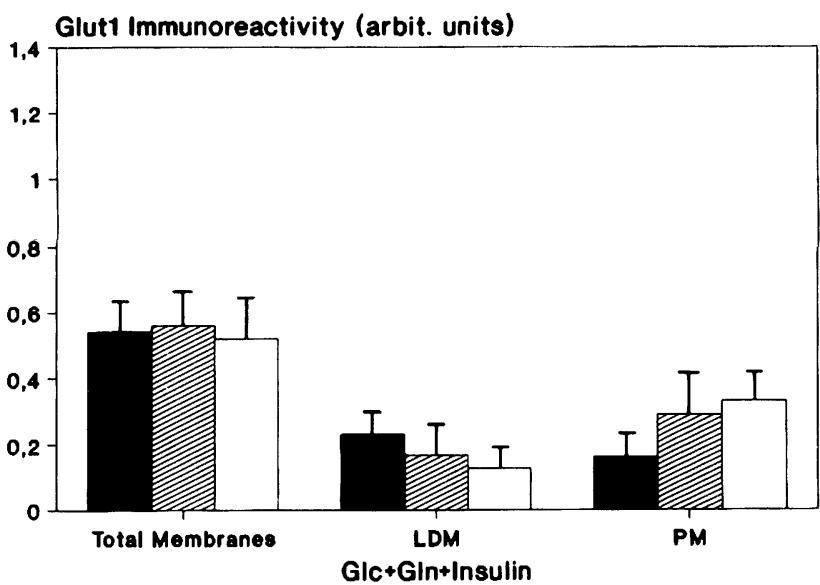

F Responsiveness of Glut1 Translocation

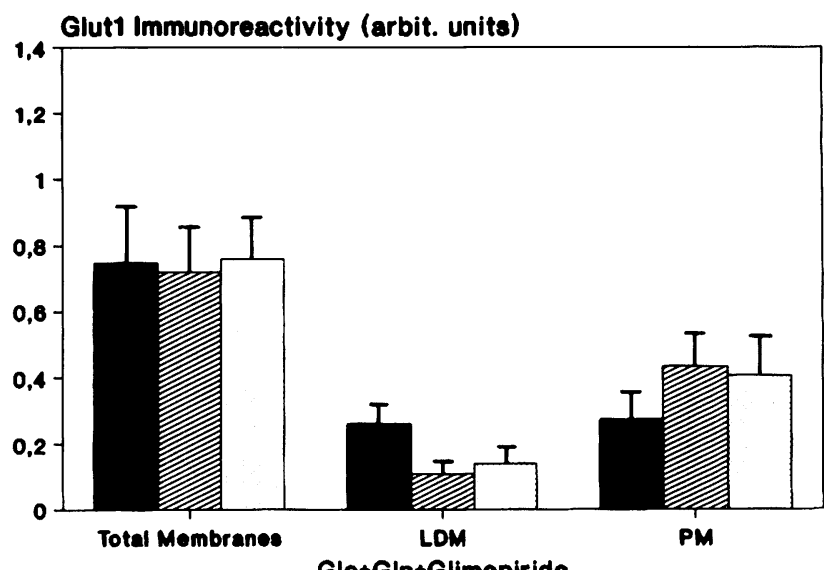

FIG. 6. Quantitation of the immunoblot data of Fig. 5. The radioactive filter strips were sliced and counted for radioactivity in a $r$ counter. The amount of GLUT4 and GLUT1, respectively, in total membranes of adipocytes cultured in glucose medium and in the basal state (without insulin and glimepiride stimulation) was set at 1.0 arbitrary units. Each value represents the mean of four fractionations with different cell preparations. $A, C, E$ : Anti-GLUT4; B, D, F: anti-GLUT1; A, B: glucose medium; C, D: glucose/glutamine/insulin medium; $E$, $F$ : glucose/glutamine/glimepiride

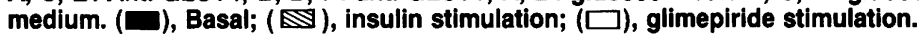


of GLUT4 and GLUT1 is significantly reduced after primary culture of the adipocytes with glucose and glutamine in the presence of either insulin (Fig. $6 \mathrm{C}$ and $D$ ) or, to a lesser degree, glimepiride (Fig. $6 E$ and $F$ ). Subsequent acute challenge of insulin or glimepiride of insulin-resistant cells does not affect total GLUT4 and GLUT1 protein (Fig. 6C-F).

Glucosamine is involved in desensitization of glucose transport by insulin and glimepiride. Marshall et al. (21) have demonstrated that glucosamine is able to substitute for glucose and glutamine in inducing desensitization of the glucose transport system. Therefore, we studied whether glimepiride is able to circumvent the glucosamine-induced insulin resistance. Figure $7 \mathrm{~A}$ confirms that insulin in combination with glucose plus glutamine, but not with either compound alone, reduces the maximal insulin responsiveness but leaves the responsiveness toward glimepiride largely unimpaired. Glucosamine, but only in combination with insulin, reduces the maximal insulin but not glimepiride responsiveness. These observations indicate that glimepiride bypasses the desensitization of the glucose transport system at a site downstream of the formation of glucosamine from glucose and glutamine.

Next we studied whether glimepiride, like insulin, desensitizes glucose transport via formation of glucosamine. Glimepiride in combination with glucosamine present during primary culture causes an - 50\% rêduciction of the maximal insulin responsiveness similar to the effect of glucose plus glutamine (Fig. 7B). Glimepiride combined with either glucose or glutamine alone leads to only a slight impairment. Under all conditions of primary culture, the maximal loss of glimepiride responsiveness does not exceed $20 \%$. The ability of glucosamine to induce insulin resistance if present together with insulin or glimepiride strongly suggests that both agents use similar mechanisms for desensitization of glucose transport that may involve increased formation of hexosamine derivatives.

Desensitization of glucose transport in primary cultured adipocytes is accompanied by increased phosphorylation of GLUT4. Finally, we studied whether increased phosphorylation of GLUT molecules represents the molecular mechanism for their desensitization toward insulin as may be deduced from some recent observations $(46,47,47 a)$. Therefore, we investigated the phosphorylation state of GLUT4 in rat adipocytes during desensitization of the glucose transport system. For this, adipocytes were cultured for $20 \mathrm{~h}$ with high levels of glucose, glutamine, and insulin. Subsequently, the cells were incubated in the presence of either ${ }^{32} \mathrm{Pi}$ or $\left.{ }^{35} \mathrm{~S}\right]$ methionine under the same conditions for $2 \mathrm{~h}$ to achieve steady-state labeling of the cells before short-term treatment with insulin or glimepiride. After immunoprecipitation of solubilized total membranes, LDM and PM fractions with anti-GLUT4 antibodies, the ${ }^{35}$ S]methionine- and ${ }^{32}$ Pi-labeled GLUT4 molecules were analyzed by SDS-PAGE. As can be seen from the fluorograms of the gels (Fig. 8), induction of insulin resistance by primary culture of the adipocytes in glucose/glutamine/ insulin medium reduces the total amount of GLUT4

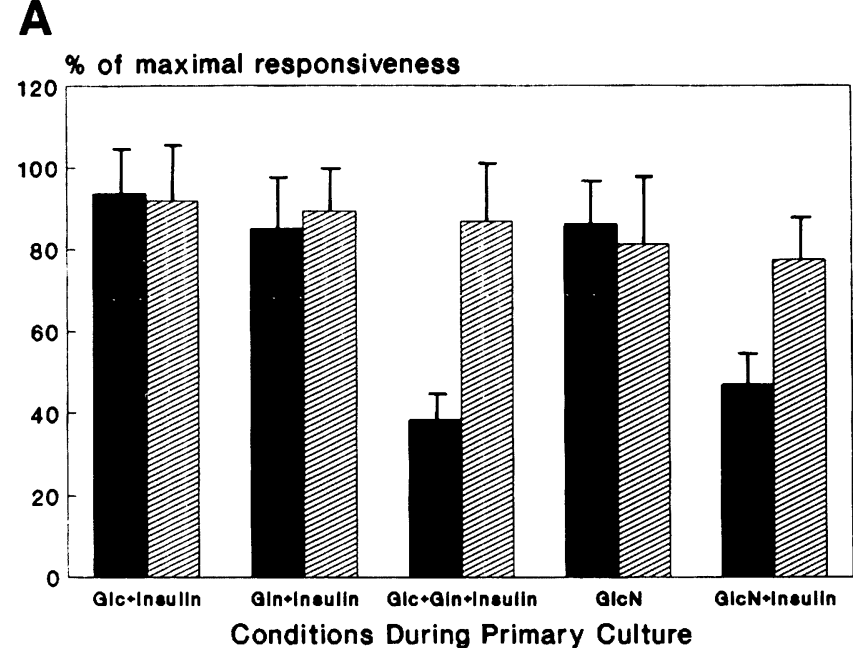

B

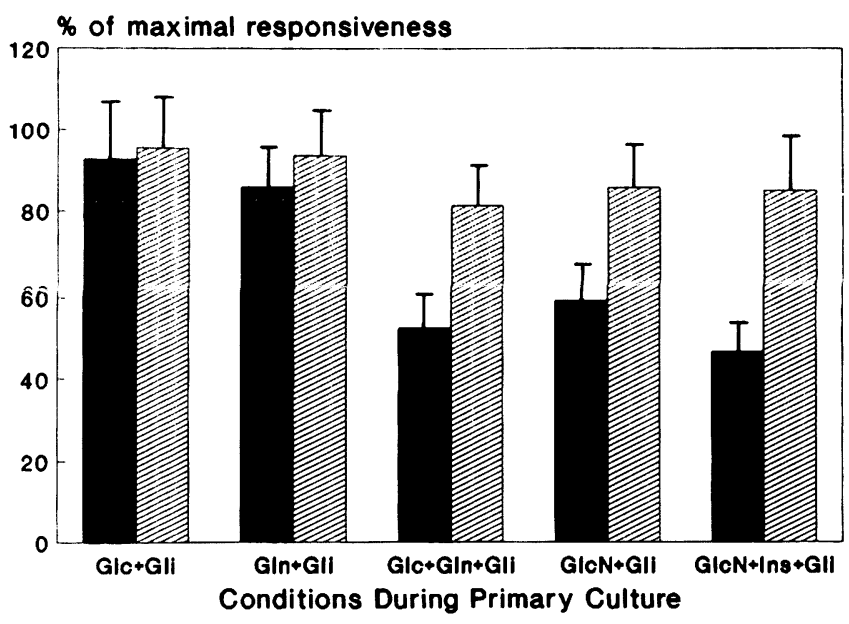

FIG. 7. Effect of glucosamine during primary culture on insulin $(A)$ and glimepiride $(B)$ responsiveness of glucose transport. Adipocytes were cultured in medium containing various combinations of insulin (10 $\mathrm{nM})$, glimepiride $(50 \mu \mathrm{M})$, glucose $(20 \mathrm{mM})$, glutamine $(16 \mathrm{mM})$, and glucosamine $(2 \mathrm{mM})$ for $20 \mathrm{~h}$ at $37^{\circ} \mathrm{C}$ as indicated. After full deactivation of the glucose transport system, portions of the cells were incubated in the presence of $10 \mathrm{nM}$ insulin $(\square)$ or $50 \mu \mathrm{M}$ glimepiride (T) for $20 \mathrm{~min}$ at $37^{\circ} \mathrm{C}$ and subsequently assayed for 2-deoxyglucose transport. The initial transport velocity of cells cultured in glucose medlum during the $20-\mathrm{h}$ period was set at $100 \%$ of maximal responsiveness for insulin ( $\square$ ) and glimepiride (ש) stimulation, respectively. Each value represents the mean \pm SE of nine measurements with three different cell preprarations.

protein synthesized during $2 \mathrm{~h}$ (compare Fig. $8 A$ and $B$, lanes 1,4 , and 7) and impairs the insulin-stimulated redistribution of GLUT4 from LDM to PM (compare Fig. $8 A$ and $B$, lanes 5 and 6 ). The quantitative evaluation of the data (Fig. $8 C$ and $8 D$ ) proves that the subcellular distribution of $\left[{ }^{35} \mathrm{~S}\right] \mathrm{methionine-labeled}$ and immunoprecipitated GLUT4 closely reflects the amount of GLUT4 in the LDM and PM fractions as revealed by immunoblotting (Fig. 5). Despite the loss of GLUT4 protein in desensitized cells, the total amount of ${ }^{32} \mathrm{Pi}$-labeled GLUT4 increases 2.9 -fold in these cells (Fig. $8 A$ and $B$, lanes 10 , 13 , and $16 ; 8 E$ and $F$. Correction for the different amounts of immunoprecipitated $\left.{ }^{35} \mathrm{~S}\right]$ methionine-labeled 


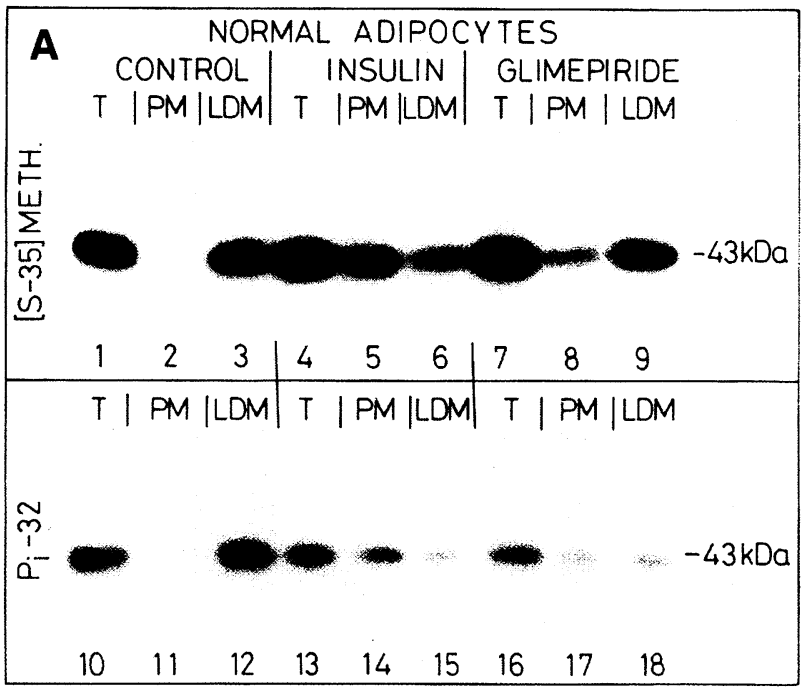

C Responsiveness of Glut4 Translocation

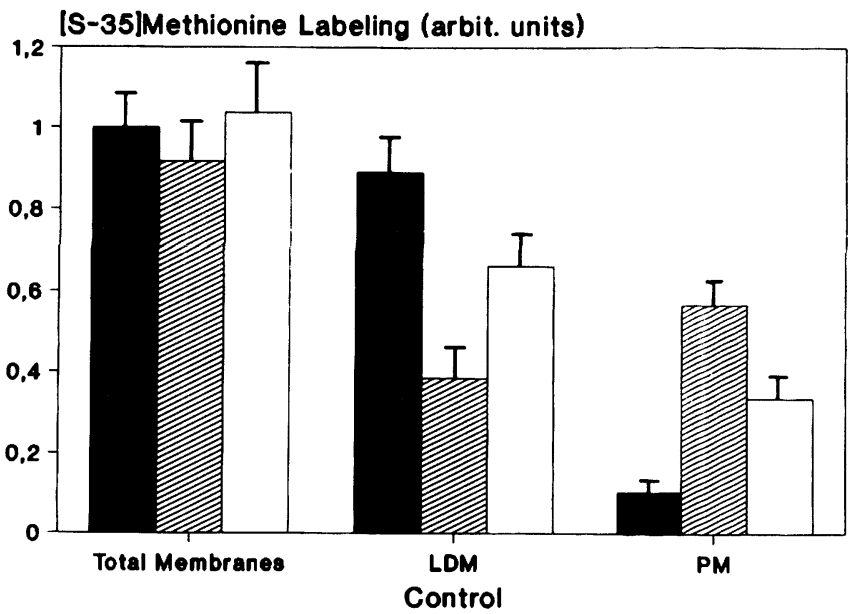

E Responsiveness of Glut4 Translocation

[P-32]Phosphate Labeling (arbit. units)

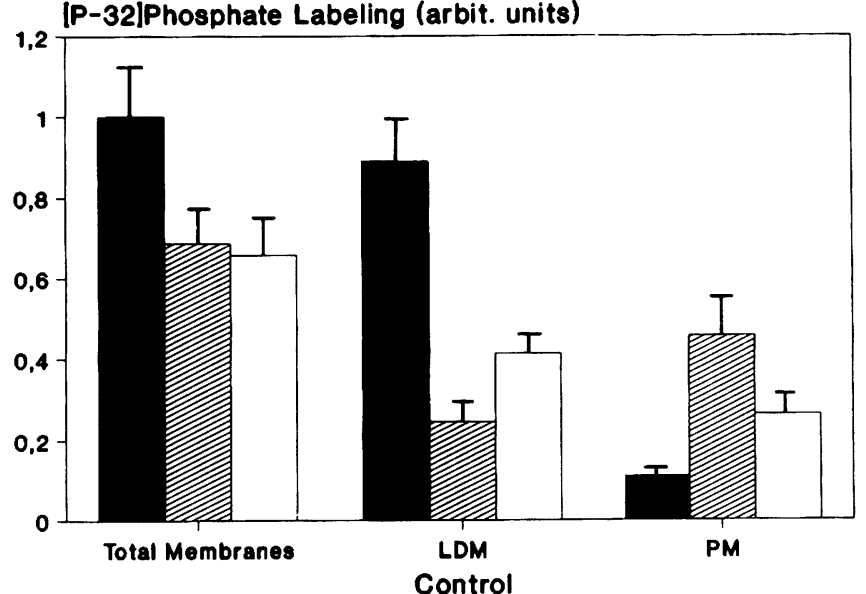

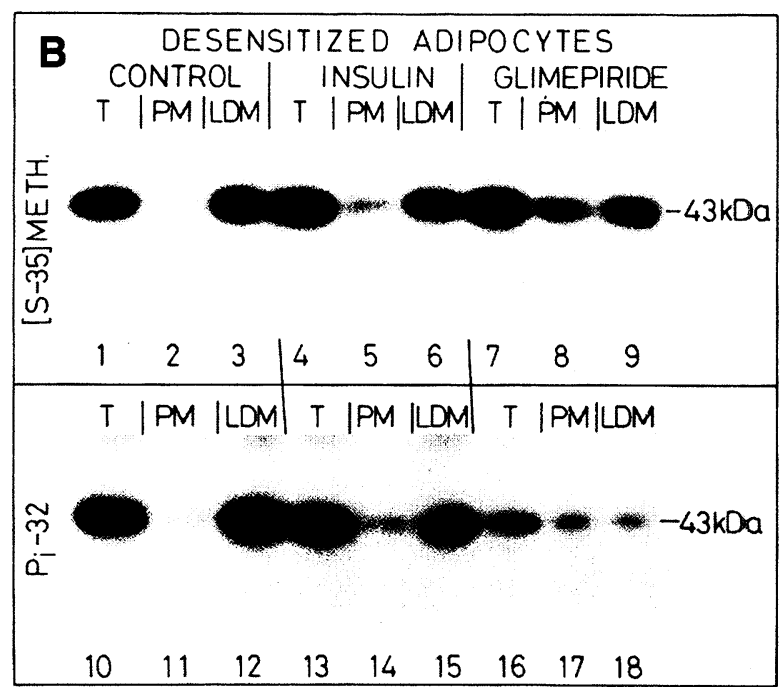

D Responsiveness of Glut4 Translocation

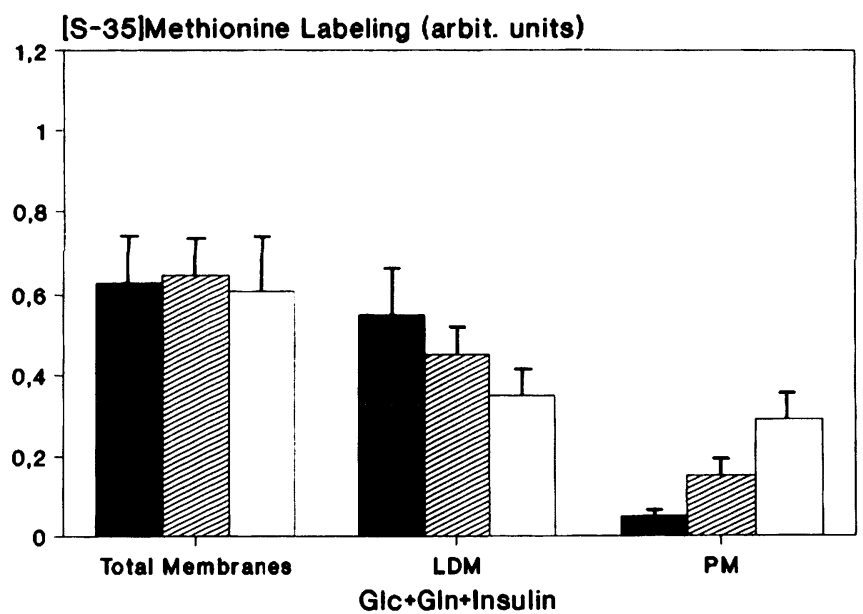

F Responsiveness of Glut4 Translocation

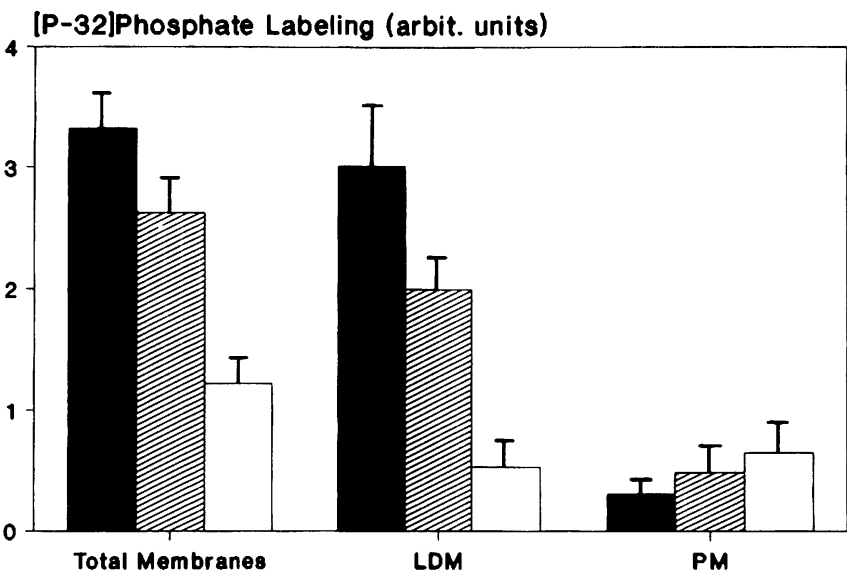

Glc + GIn+Insulin

FIG. 8. Effect of primary culture and treatment with insulin and glimepiride of adipocytes on the phosphorylation of GLUT4. Adipocytes were cultured in glucose medium (normal, $A, C, E$ ) and glucose/glutamine/insulin medium (desensitized, $B, D, F$ ) containing $0.1 \mathrm{mM}$ sodium phosphate for $20 \mathrm{~h}$ at $37^{\circ} \mathrm{C}$. Subsequently, the incubation was continued with $\left[{ }^{35} \mathrm{~S}\right]$ methionine (lanes 1-9) or ${ }^{32} \mathrm{P}$ (lanes 10-18) for $2 \mathrm{~h}$. After full deactivation of the glucose transport system, the washed cells were incubated in the absence (Control) or presence of $10 \mathrm{nM}$ insulin and $20 \mu \mathrm{M}$ glimepiride for $20 \mathrm{~min}$ at $37^{\circ} \mathrm{C}$ (during the periods of glucose transport deactivation and subsequent treatment with insulin/glimepiride, the same specific activity of ${ }^{32} \mathrm{Pi}$ was present as during the initial period of steady-state labeling [lanes 9-18], and the $\left[{ }^{35}\right.$ S] methionine incorporation was chased by the addition of $10 \mathrm{mM}$ unlabeled methionine [lanes 1-9]), and washed and homogenized in the presence of $1 \mathrm{mM}$ sodium phosphate. From one half of the homogenate, total membranes ( $T$ ) were prepared. The other half was fractionated into LDM and PM as described in METHODS. 
GLUT4 results in a 3.0- to 5.3-fold increase in the amount of GLUT4 phosphoprotein in total membranes, LDM and PM of desensitized versus normal adipocytes (Table 3 ). This suggests that insulin resistance of the adipocyte glucose transport in vitro is accompanied by significant phosphorylation of GLUT4 in both LDM and PM.

Glimepiride reduces the phosphorylation state of GLUT4 in insulin-resistant adipocytes. Short-term incubation of desensitized adipocytes with both insulin (10 $\mathrm{nM})$ and glimepiride $(20 \mu \mathrm{M})$ causes a pronounced decrease of the GLUT4 phosphorylation state in total membranes, LDM and PM (Fig. 8B, lanes 13-18, and $8 F$. However, glimepiride is much more effective than insulin (Table 3). The ratios in the amount of GLUT4 phosphoprotein in LDM and PM only slightly differ between control and insulin treatment. In contrast, glimepiride treatment causes preferential reduction of the GLUT4 phosphorylation state in LDM versus PM, however, only in desensitized cells (Table 3). Acute treatment of normal adipocytes (which contain only a modest amount of GLUT4 phosphoprotein) with insulin or glimepiride reduces GLUT4 phosphorylation to a similar but minor extent (Fig. 8A, lanes 13-18, and 8E).

In a control experiment (Fig. 9), we tested whether the ${ }^{32} \mathrm{Pi}$-labeled and immunoprecipitated $43,000-M_{\mathrm{r}}$ protein is identical to GLUT4. Cell homogenates from ${ }^{32} \mathrm{Pi}$-labeled normal and desensitized adipocytes that have been incubated in the absence or presence of insulin and glimepiride were immunoprecipitated with a polyclonal anti-GLUT4 antibody (raised against the 16 $\mathrm{COOH}$-terminal amino acids of rat GLUT4) or preimmune serum. After SDS-PAGE of the immunoprecipitates, the radiolabeled $43,000-M_{r}$ protein bands, identified by autoradiography (Fig. 9, lanes 1-5), were eluted from the gel, separated by SDS-PAGE, and assayed for antiGLUT4 immunoreactivity by Western blotting with a different polyclonal anti-GLUT4 antibody (raised against purified rat GLUT4) and detection of antibody binding by a chemiluminescence assay. The $X$-ray film exposed to the nitrocellulose sheet (Fig. 9, lanes 6-10) demonstrates the identity of the phosphorylated and (with anti-GLUT4 antiserum) immunoprecipitated $43,000-M_{r}$ protein (Fig. 9, lanes 2-5) with GLUT4 (Fig. 9, lanes 7-10) and thus, together with the nonreactivity of the preimmune serum (Fig. 9, lanes 1 and 6), the specificity of the immunoprecipitation. Furthermore, the experiment confirms that desensitized adipocytes contain less GLUT4 protein than normal adipocytes, which is, however, in a more heavily phosphorylated state (compare Fig. 9 lanes 2 and 3 with lanes 7 and 8). Again, acute glimepiride treatment does not affect the total amount of GLUT4 protein but significantly reduces the amount of GLUT4 phosphoprotein (Fig. 9, lanes 5 and 10). These data suggest that glimepiride decreases the phosphorylation of GLUT4, especially in the LDM fraction of desensitized adipocytes, to a higher degree than insulin.

\section{DISCUSSION}

The aim of this study was to elucidate direct effects of sulfonylurea drugs on glucose transport in insulin-resistant isolated rat adipocytes. The insulin resistance was induced by hyperinsulinemic and hyperglycemic conditions in primary culture. The reduced maximal insulin responsiveness and sensitivity of glucose transport in these cells may originate from a postinsulin binding and coupling defect between the insulin receptor and the translocation machinery and synthesis of GLUT molecules, because we observed impaired redistribution of GLUT1 and GLUT4 from LDM to PM and a lowered total number of GLUT1 and GLUT4. Both reduced translocation and synthesis of GLUT4 are characteristic features for adipose tissue of obese and nonobese NIDDM patients $(48,49)$. This suggests similar mechanisms of fat cell insulin resistance operating in vivo and in vitro. Marshall et al. (50) previously described the effect on translocation but could not find any effect on the total GLUT number. The reason for this discrepancy is not clear but may be related to the different methods used for the identification of GLUT, specific antibodies in our study versus cytochalasin B binding (50)

Effects of glimepiride on glucose transport and GLUT translocation in adipocytes. In insulin-resistant cells, the sulfonylurea drug glimepiride, in the absence of insulin, stimulates glucose transport with only slightly reduced sensitivity and responsiveness compared with normal cells. In fact, a higher maximal initial transport velocity is yielded in insulin-resistant cells by glimepiride than by insulin (Fig. 4A). The glucose transport stimulation may rely at least in part on the increased expression of GLUT1 and GLUT4 at the cell surface in response to drug. This is caused by enhanced translocation rather than increased synthesis of GLUT1 and GLUT4 in both normal and desensitized adipocytes. Thus, this study demonstrates, for the first time, stimulation of GLUT recruitment from LDM to PM by a sulfonylurea drug in the absence of insulin. In addition, these compounds potentiate the insulin-induced redistribution (51).

The molecular site(s) of glimepiride action in adipocytes. The data suggest that glimepiride interacts with the signaling cascade between the insulin receptor and the translocation apparatus downstream of the molecular defect of glucosamine-induced desensitization. The observation that glimepiride present during the primary culture instead of insulin also leads to insulin resistance of the glucose transport provides further evidence for the role of increased glucose influx for desensitization. Interestingly, a glycosyl-phosphatidylinositol-specific phospholipase $\mathrm{C}$ becomes activated by glimepiride in cultured 3T3 adipocytes (41) and in normal and insulinresistant isolated rat adipocytes (G.M., S.W., and A. Korndorfer, unpublished observations). The observation that activation of this phospholipase requires GLUT translocation and experimental evidence from other lab-

Equivalent amounts of protein were solubilized and subjected to immunoprecipitation using anti-GLUT4 peptide antibodies adsorbed to protein A-Sepharose. The collected and washed immunoprecipitates were analyzed by SDS-PAGE and fluorography. The results of one typical experiment repeated 4 times are shown in $A$ and $B$. The radioactivities contained in the gel bands of four independent experiments were determined by a Berthold scanner. The radiolabel of the immunoprecipitated GLUT4 in total membranes ( $T$ ) of adipocytes cultured in glucose medium and in the basal state was set at 1.0 arbitrary units. Each value represents the mean of four fractionations \pm SE (C-F). 
TABLE 3

$\left[{ }^{32} \mathrm{P}\right]:\left[{ }^{35} \mathrm{~S}\right]$ ratio of immunoprecipitated GLUT4 in membrane fractions of metabolically labeled normal and desensitized adipocytes after control, acute insulin, and glimepiride treatment calculated from Fig. 8

\begin{tabular}{lccccccc}
\hline & \multicolumn{3}{c}{ Normal adipocytes } & & \multicolumn{3}{c}{ Desensitized adipocytes } \\
\cline { 2 - 3 } & Control & Insulin & Glimepiride & & Control & Insulin & Glimepiride \\
\hline Total membrane & 1 & 0.75 & 0.63 & & 5.27 & 4.04 & 2.01 \\
LDM & 1.01 & 0.64 & 0.62 & & 5.47 & 4.44 & 1.52 \\
PM & 1.05 & 0.80 & 0.78 & & 3.02 & 3.26 & 2.25 \\
LDM:PM & 0.95 & 0.80 & 0.79 & & 1.81 & 1.36 & 0.68 \\
\hline
\end{tabular}

The last line indicates the ratio of GLUT4 phosphoprotein in LDM and PM.

oratories (52) argue against direct regulation of glucose transport via phospholipase $\mathrm{C}$ cleavage products (phosphoinositolglycan headgroups) and suggest a different site of glimepiride action on glucose transport.

Regulation of GLUT4 phosphorylation by insulin and glimepiride. Reports from several laboratories indicate that phosphorylation of GLUT4 at serine/threonine residues by isoproterenol-stimulated PKA (46) or $\mathrm{Ca}^{2+} /$ calmodulin-dependent protein kinase (53) or inhibition of protein phosphatases 1 and $2 \mathrm{~A}$ by okadaic acid $(47,47 a)$ reduces the insulin-stimulated glucose transport in isolated rat adipocytes. Therefore, one possible mechanism for desensitization of the glucose transport and GLUT translocation for insulin stimulation may reside in an increased phosphorylation state of GLUT4. If this is true, activation of glucose transport and GLUT translocation by treatment of desensitized adipocytes with glimepiride should be correlated with diminished GLUT4 phosphorylation. This is exactly what we observed with GLUT4 from both LDM and PM of desensitized adipocytes before and after glimepiride treatment. In contrast, insulin is less effective in reducing GLUT4 phosphorylation. Because extensive GLUT4 phosphorylation in insulin-resistant cells can be observed within $2 \mathrm{~h}$, GLUT4 has to undergo a rapid phosphorylation/dephosphorylation cycle. Its equilibrium is shifted to phosphorylation during desensitization and dephosphorylation during short-term glimepiride and (to a minor degree) insulin treatment.

These modifications may be provoked by stimulation of GLUT4 protein kinases (i.e., PKA, PKC) during desensitization, which are inhibited by glimepiride (and insulin). Alternatively, GLUT4 protein phosphatase(s) may be inhibited during desensitization but stimulated by glimepiride (and insulin). Although kinases/phosphatases acting on GLUT4 in rat adipocytes have not been identified unequivocally so far $(54,55)$, we prefer the former possibility for the following reasons. First, it has been shown in isolated adipocytes that hyperglycemia- and catecholamine-induced insulin resistance are associated with increased PKC and PKA activity, respectively, and decreased insulin receptor kinase $(56,57)$ and glucose transport activity (58). This may be responsible for the downregulation of the insulin signaling cascade. It is possible that similar mechanisms operate during primary culture of rat adipocytes in the presence of high concentrations of insulin and glucose and in NIDDM in the presence of high levels of insulin or counterregulatory hormones that elevate CAMP levels (59). Second, we were able to demonstrate that incubation of rat adipocytes with glimepiride lowers intracellular CAMP levels via stimulation of CAMP phosphodiesterase and reduces the intrinsic activity of PKA (G.M., S.W., unpublished observations). This has been described previously for other sulfonylureas in rat hepatocytes and adipocytes $(60,61)$. Third, participation of PKA in phosphorylation and densensitization of GLUT4 is suggested by in vitro phosphorylation experiments of immunoprecipitated GLUT4 from normal and desensitized adipocytes with [22P]ATP and purified PKA from bovine heart (data not shown). The significantly reduced CAMP-dependent ${ }^{32} \mathrm{Pi}$-incorporation into GLUT4 in desensitized versus normal adipocytes indicates that GLUT4 molecules had already been phosphorylated at sites recognized by PKA during the period of desensitization.

Regulation of glucose transport in adipocytes by GLUT phosphorylation. Interestingly, Begum and Draznin (62) previously reported increased GLUT4 phosphorylation in adipocytes from STZ-induced diabetic rats (62). In contrast to normal cells, insulin did not cause GLUT4 dephosphorylation in diabetic adipocytes. The authors presented evidence that the highly phosphorylated GLUT4 in the PM of diabetic adipocytes does not interact with particulate phosphatases. This provides another explanation for the shift in the phosphorylation/dephosphorylation equilibrium of GLUT4 in the diabetic state. However, whereas the GLUT4 phenotype is very similar between their animal model and our in vitro model of desensitized fat cells, the molecular mechanisms for altered GLUT4 phosphorylation may differ between insulin resistance caused by hypo- and hyperinsulinemia.

The correlation between the GLUT4 phosphorylation state and glucose transport velocity in normal, desensitized, and desensitized and subsequently glimepiridetreated rat adipocytes strongly argues for regulation of glucose transport by phosphorylation. Operation of this mechanism during induction of insulin resistance in vitro is also suggested by recent studies of Draznin et al. $(63,64)$ with isolated rat adipocytes incubated with parathyroid hormone (63) or ATP and thapsigargin (64), which both increase cytosolic calcium. These conditions lead to insulin-resistant glucose transport as well as phosphorylation of GLUT4 and reduced insulin-stimulated dephosphorylation of GLUT4. These results strengthen the view that in diverse cellular models of insulin resistance, reduced insulin-stimulated glucose transport is caused 


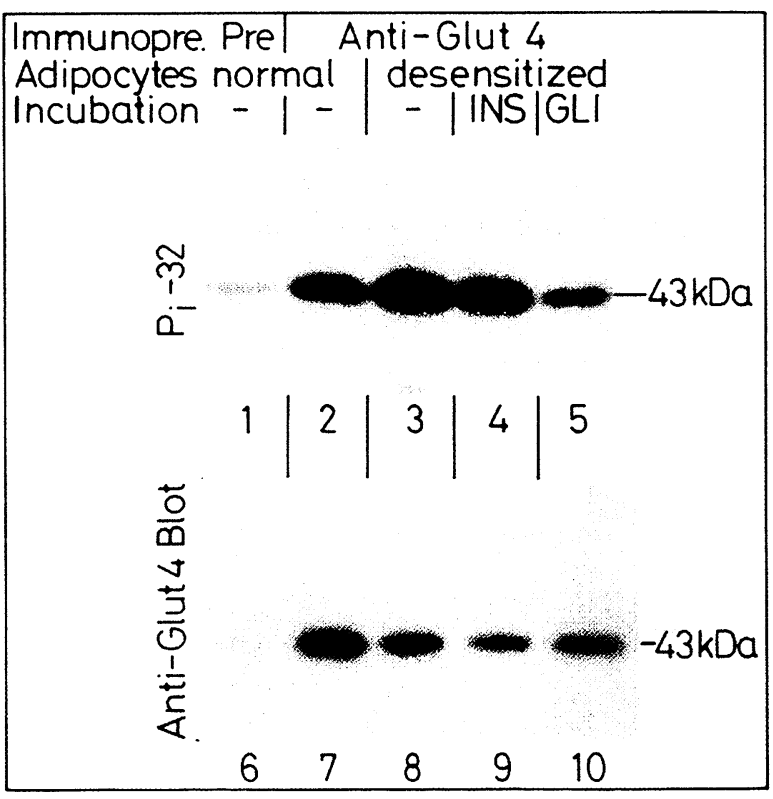

FIG. 9. Specificity of the immunoprecipitation of GLUT4. Adipocytes were cultured in glucose (normal) or glucose/glutamine/insulin medium (desensitized) for $20 \mathrm{~h}$ at $37^{\circ} \mathrm{C}$, then labeled with ${ }^{32 \mathrm{Pi}}$ for $2 \mathrm{~h}$ at $37^{\circ} \mathrm{C}$, and finally incubated in the absence or presence of insulin (10 $\mathrm{nM})$ and glimepiride $(20 \mu \mathrm{M})$ for $20 \mathrm{~min}$ at $37^{\circ} \mathrm{C}$ as described for Fig. 8. Cell homogenates were prepared and immunoprecipitated with preimmune serum (Pre) or anti-GLUT4 antiserum adsorped to protein A-Sepharose. The collected immunoprecipitates were separated by SDS-PAGE and analyzed by autoradiography (lanes 1-5). The protein contained in the radiolabeled $43,000-M$, band was electroeluted from the sliced gel strip, subjected to SDS-PAGE, and transferred to nitrocellulose filter, which was used for immunoblot analysis with a different polyclonal rabbit anti-GLUT4 antibody (raised against total rat GLUT4) using anti-rabbit IgG coupled to alkaline phosphatase and a chemiluminescence assay for detection of antibody binding (lanes 6-10).

by the loss of insulin's ability to elicit dephosphorylation of GLUT4.

However, the effect of GLUT4 phosphorylation on glucose transport may differ between the different in vitro models of insulin resistance. The present experimental evidence that phosphorylation of GLUT4 and its cellular distribution between LDM and PM are regulated in parallel, i.e., increased phosphorylation of GLUT4 is correlated with decreased cell surface expression (Fig. 8), suggests that phosphorylation of GLUT4 may act as a signal for its endocytosis (as shown for IGF-II, [65]) or retention in intracellular stores. The observation that glimepiride treatment preferentially diminishes the phosphorylation state of GLUT4 in LDM (Table 3) favors the possibility that phosphorylation of GLUT4 functions as a retention signal for the intracellular compartment. Interestingly, isolated PM vesicles containing phosphorylated GLUT4 exhibited decreased glucose transport compared with GLUT4 dephosphorylated in response to insulin (63). This raises the possibility that the increased phosphorylation state of GLUT4 interferes with the insulin-stimulated intrinsic glucose transport activity of GLUT4. It remains to be elucidated whether the different underlying mechanisms of glucose transport regulation by phosphorylation, which are not mutually exclusive, depend on the type of insulin resistance induced in vitro and are operating in vivo.

Extrapancreatic effects of sulfonylureas in vitro and in vivo. In addition to adipose tissue, prolonged exposure to high glucose has been reported to acutely and chronically downregulate the glucose transport system in skeletal muscle, which represents the major site for insulin-dependent glucose disposal (66). It will be interesting to see in future studies whether glimepiride will compensate the lower number of GLUT4 in PM of muscle cells in the basal and insulin-stimulated state. The direct stimulation of glucose transport in the isolated rat diaphragm (67), perfused rat hindlimb (68), and cultured muscle cells $(7,8)$ by sulfonylurea drugs suggests similar modes of action of these compounds in muscle and adipose tissue.

The stimulation of glucose transport by glimepiride in insulin-resistant adipocytes, which persists even after long-term treatment, may have important implications for the therapy of NIDDM. In contrast to insulin, glimepiride partially circumvents downregulation of the cell surface GLUT expression by hyperinsulinemia. This feature may contribute to the long-lasting blood glucose-lowering capacity of this drug (23), even after chronic therapy. The physiological significance of the extrapancreatic action of glimepiride is not weakened by the low total serum levels of glimepiride (200-400 nM at maximum, E. Draegêr, unipublished observations). At this concentration, small but significant increases of glucose transport and GLUT translocation are already observed in vitro. The situation may be different when the insulin resistance is induced by hypoinsulinemia instead of hyperinsulinemia because glucose transport in adipocytes isolated from STZ-induced diabetic rats is not stimulated by sulfonylureas in the absence of insulin (15). Furthermore, these drugs have no effect on in vivo insulin action in STZinduced diabetic rats under conditions of severe insulin deficiency. However, in the case of simultaneous administration of insulin using the euglycemic clamp procedure, glimepiride potentiates insulin-stimulated glucose disposal in peripheral tissues (I. Ohsawa, unpublished observations). Possibly, the expression of a component, which is involved in mediating the glimepiride signal to the translocation machinery, is under control of insulin and thus missing in the insulinopenic state.

Taken together, this study fits into a speculative framework for a unifying theory of sulfonylurea action based on their capacity to directly stimulate insulin secretion in glucose-insensitive pancreatic $\beta$-cells and GLUT translocation in insulin-resistant fat and muscle cells. Both events involve regulated exocytosis and fusion of intracellular vesicles, i.e., secretory granules and insulinsensitive glucose transporter vesicles budding from tubulo-vesicular structures of the trans-Golgi reticulum $(69,70)$, respectively, with the PM, which may be controlled by similar mechanisms. Sulfonylurea receptors have been described for both rat $\beta$-cells (71) and adipocytes (72), but their structural relationship remained unclear. All the other effects of sulfonylurea drugs on glucose metabolism and insulin sensitivity observed on isolated cells and in vivo may represent secondary 
events following altered glucose influx and blood glucose levels, respectively. In support of this hypothesis, correction of hyperglycemia with phlorizin has been reported to normalize insulin action in diabetic rats $(73,74)$.

\section{ACKNOWLEDGMENTS}

The authors wish to thank Dr. E. Draeger (Hoechst AG, Frankfurt) and Dr. W. Bandlow (Genetic Department, University of Munich) for valuable discussions, E.A. Dearey for technical assistance during some experiments, Drs. P. Hale and A. Diedenhofen (Hoechst AG, Frankfurt) for critical reading of the manuscript, and Dr. T. Kreis (EMBL, Heidelberg) and Dr. G.V. Jagow (University of Frankfurt) for kindly providing the antisera.

\section{REFERENCES}

1. Yalow RS, Black $H$, Villazon $M$, Berson S: Comparison of plasma insulin levels following administration of tolbutamide and glucose. Diabetes 9:356-62, 1960

2. Feldman JM, Levobitz HE: Endocrine and metabolic effects of glibenclamide: evidence for an extrapancreatic mechanism of action. Diabetes 20:745-55, 1971

3. Hirshman MF, Horton ES: Glyburide increases insulin sensitivity and responsiveness in peripheral tissues of the rat as determined by the glucose clamp technique. Endocrinology 126:2407-11, 1990

4. Greenfield MS, Doberne $L$, Rosenthal M, Schulz B, Widstrom A, Reaven GM: Effect of sulfonylurea treatment on in vivo insulin secretion and action in patients with non-insulin-dependent diabetes mellitus. Diabetes 31:307-12, 1982

5. Kolterman OG, Gray RS, Shapiro G, Scarlett JA, Griffin J, Olefsky JM: The acute and chronic effects of sulfonylurea therapy in type II diabetic subjects. Diabetes 33:346-54, 1984

6. Altan N, Altan VM, Mikolay L, Larner J, Schwartz CFW: Insulin-like and insulin-enhancing effects of the sulfonylurea glyburide on rat adipose glycogen synthase. Diabetes 34:281-86, 1985

7. Rogers BJ, Standaert ML, Pollet RJ: Direct effects of sulfonylurea agents on glucose transport in the $\mathrm{BC} 3 \mathrm{H}-1$ myocyte. Diabetes 36:1292-96, 1987

8. Cooper DR, Vila MC, Watson JE, Nair G, Pollet RJ, Standaert M, Farese RV: Sulfonylurea-stimulated glucose transport association with diacylglycerol-like activation of protein kinase $\mathrm{C}$ in $\mathrm{BC} 3 \mathrm{H}-1$ myocytes. Diabetes 39:1399-407, 1990

9. Davidson MB, Molnar IG, Furman A, Yamaguchi D: Glyburidestimulated glucose transport in cultured muscle cells via protein kinase $\mathrm{C}-$ mediated pathway requiring new protein synthesis. Diabetes 40:1531-37, 1991

10. Zuber MX, Wang S-M, Thammavaram KV, Reed DK, Reed BC: Elevation of the number of cell-surface insulin receptors and the rate of 2-deoxyglucose uptake by exposure of 3T3-L1 adipocytes to tolbutamide. J Biol Chem 260:14045-52, 1985

11. Farese RV, Ishizuka T, Standaert ML, Cooper DR: Sulfonylureas activate glucose transport and protein kinase $C$ in rat adipocytes. Metabolism 40:196-200, 1991

12. Jacobs DB, Hayes GR, Lockwood DH: Effect of chlorpropamide on glucose transport in rat adipocytes in the absence of changes in insulin binding and receptor-associated tyrosine kinase activity. Metabolism 36:548-54, 1987

13. Caren R, Corbo L: The potentiation of exogeneous insulin by tolbutamide in depancreatized dogs. J Clin Invest 36:1546-50, 1957

14. Bak JF, Schmitz O, Schwartz Sorensen N, Pedersen O: Postreceptor effects of sulfonylurea on skeletal muscle glycogen synthase activity in type II diabetic patients. Diabetes 38:1343-48, 1989

15. Jacobs DB, Hayes GR, Lockwood DH: In vitro effects of sulfonylurea on glucose transport and translocation of glucose transporters in adipocytes from streptozocin-induced diabetic rats. Diabetes 38 : 205-11, 1989

16. Salhanick Al, Konowitz $P$, Amatruda JM: Potentiation of insulin action by a sulfonylurea in primary cultures of hepatocytes from normal and diabetic rats. Diabetes 32:206-12, 1983

17. Karnieli E, Hissin PJ, Simpson IA, Salans LB, Cushman SW: A possible mechanism of insulin resistance in the rat adipose cell in stretozotocin-induced diabetes mellitus: depletion of intracellular glucose transport systems. J Clin Invest 68:811-14, 1981

18. Olefsky JM, Garvey $T$, Henry R, Brillon D, Matthaei S, Freidenberg GR: Cellular mechanisms of insulin resistance in non-insulin-depen- dent (type II) diabetes mellitus. Am J Med 85 (Suppl. 5A):86-105, 1988

19. Kolterman OG, Gray RS, Griffin J, Burstein P, Insel J, Scarlett JA, Olefsky JM: Receptor and postreceptor defects contribute to the insulin resistance in non-insulin-dependent diabetes mellitus. J Clin Invest 68:957-69, 1981

20. Dall'aglio $E$, Chang $H$, Hollenbeck $C B$, Mondon $C E$, Sims $C$, Reaven GM: In vivo and in vitro resistance to maximal insulin-stimulated glucose disposal in insulin deficiency. Am J Physiol 249:E312-16, 1985

21. Marshall S, Bacote V. Traxinger RR: Discovery of a metabolic pathway mediating glucose-induced desensitization of the glucose transport system. J Biol Chem 266:4706-12, 1991

22. Marshall S, Garvey WT, Traxinger RR: New insights into the metabolic regulation of insulin action and insulin resistance: role of glucose and amino acids. FASEB J 5:3031-36, 1991

23. Geisen K.: Special pharmacology of the new sulfonylurea glimepiride. Arzneimittelforschung 38:1120-30, 1988

24. Gazzano $H$, Kowalski A, Fehlmann $M$, Van Obberghen $E$ : Two different protein kinase activities are associated with the insulin receptor. Biochem J 216:575-82, 1983

25. Benovic JL, Bouvier M, Caron MG, Lefkowitz RJ: Regulation of adenylyl cyclase-coupled B-adrenergic receptors. Ann Rev Cell Biol 4:405-29, 1988

26. James DE, Strube M, Mueckler M: Molecular cloning and characterization of an insulin-regulatable glucose transporter. Nature 338: 83-87, 1989

27. Mueckler $M$, Caruso $C$, Baldwin SA, Panico M, Blench I, Morris HR, Allard JW, Lienhard GE, Lodish HF: Sequence and structure of a human glucose transporter. Science 229:941-45, 1985

28. Rodbell M: Metabolism of isolated fat cells. 1. Effects of hormones on glucose metabolism and lipolysis. J Biol Chem 239:375-80, 1964

29. Traxinger RR, Marshall S: Role of amino acids in modulating glucose-induced desensitization of the glucose transport system. J Biol Chem 264:20910-16, 1989

30. Marshall S, Garvey WT, Geller M: Primary culture of isolated adipocytes. J Biol Chem 259:6376-84, 1984

31. Simpson IA, Yver DR, Hissin PJ, Wardzala LJ, Karnieli E, Salans LB, Cushman SW: Insulin-stimulated translocation of glucose transporters in the isolated rat adipose cells: characterization of subcellular fractions. Biochim Biophys Acta 763:393-407, 1983

32. McKeel DW, Jarett $L$ : Preparation and characterization of a plasma membrane fraction from isolated fat cells. J Cell Biol 44:417-32. 1970

33. Foley JE, Gliemann J: Accumulation of 2-deoxyglucose against its concentration gradient in rat adipocytes. Biochim Biphys Acta 648:100-106, 1981

34. Whitesell RR, Gliemann J: Kinetic parameters of transport of 3-Omethylglucose and glucose in adipocytes. J Biol Chem 254:527683, 1979

35. Towbin $\mathrm{H}$, Staehelin T, Gordon J: Electrophoretic transfer of proteins from polyacrylamide gels to nitrocellulose sheets: procedure and some applications. Proc Natl Acad Sci USA 76:4350-54, 1979

36. Allan VJ, Kreis TE: A microtubule-binding protein associated with membranes of the Golgi apparatus. J Cell Biol 103:2229-39, 1986

37. Glynn IM: The Na-K transporting adenosine triphosphatase. In The Enzymes of Biological Membranes. Plenum, New York, 35-114, 1985

38. Laemmli UK: Cleavage of structural proteins during the assembly of the head of bacteriophage T4. Nature 227:680-85, 1970

39. Muller G, Zimmermann R: Import of honeybee prepromelittin into the endoplasmic reticulum: structural basis for independence of SRP and docking protein. EMBO $J$ 7:2099-107, 1987

40. Popov N, Schmitt M, Schulzeck S, Matthies H: Eine storungsfreie Mikromethode zur Bestimmung des Proteingehaltes in Gewebehomogenaten. Acta Biol Med Germ 34:1441-46, 1975

41. Muller $G$, Dearey EA, Punter J: The sulfonylurea drug, glimepiride, stimulates release of $\mathrm{GPI}$-anchored plasma membrane proteins from 3T3 adipocytes. Biochem J 289:509-21, 1993

42. Karnieli E, Zarnowski MJ, Hissin PJ, Simpson JA, Salans LB, Cushman SW: Preparation and characterization of plasma membrane fraction from isolated rat fat cells. J Biol Chem 256:4772-77, 1981

43. Cushman SW, Wardzala LJ: Potential mechanism of insulin action on glucose transport in the isolated rat adipose cell. $J$ Biol Chem 255:4758-62, 1980

44. Suzuki $\mathrm{K}$, Kono $\mathrm{T}$ : Evidence that insulin causes translocation of glucose transport activity to the plasma membrane from an intrcellular storage site. Proc Natl Acad Sci USA 77:2542-45, 1980

45. Gould GW, Bell Gl: Facilitative glucose transporters: an expanding family. TIBS 15:18-23, 1990

46. James DE, Hiken JF, Lawrence JC Jr: Isoproterenol stimulates 
phosphorylation of the insulin-regulatable glucose transporter in rat adipocytes. Proc Natl Acad Sci USA 86:8368-72, 1989

47. Lawrence JC Jr, Hiken JF, James DE: Stimulation of glucose transport and glucose transporter phosphorylation by okadaic acid in rat adipocytes. J Biol Chem 265:19768-76, 1990

47a.Corvera S, Jaspers S, Pasceri M: Acute inhibition of insulin-stimulated glucose transport by the phosphatase inhibitor okadaic acid J Biol Chem 266:9271-75, 1991

48. Sinha MK, Raineri-Maldonado C, Buchanan C, Pories WJ, Carter-Su C, Pilch PF, Caro JF: Adipose tissue glucose transporters in NIDDM. Diabetes 40:472-77, 1991

49. Garvey T, Huecksteadt TP, Matthaei S, Olefsky JM: Role of glucose transporters in cellular insulin resistance of type $\|$ non-insulindependent diabetes mellitus. J Clin Invest 81:1528-36, 1988

50. Garvey WT, Olefsky JM, Matthaei S, Marshall S: Glucose and insulin coregulate the glucose transport system in primary cultured adipocytes. J Biol Chem 262:189-97, 1987

51. Jacobs $D B$, Jung $C Y$ : Sulfonylurea potentiates insulin-induced recruitment of glucose transport carrier in rat adipocytes. $J$ Biol Chem 260:2593-96, 1985

52. Jarett L, Wong EHA, Macaulay SL, Smith JA: Insulin mediators from rat skeletal muscle have differential effects on insulin-sensitive pathways of intact adipocytes. Science 227:533-35, 1985

53. Reusch JE-B, Begum N, Sussman KE, Draznin B: Regulation of GLUT4 phosphorylation by intracellular calcium in adipocytes. Endocrinology 129:3269-73, 1991

54. Lawrence JC Jr, Hiken JF, James DE: Phosphorylation of the glucose transporter in rat adipocytes. Identification of the intracellular domain at the carboxyl terminus as a target for phosphorylation in intact cells and in vitro. J Biol Chem 265:2324-32, 1990

55. Gibbs EM, Allard WJ, Lienhard GE: The glucose transporter in 3T3-L1 adipocytes is phosphorylated in response to phorbol ester but not in response to insulin. J Biol Chem 261:16597-603, 1986

56. Ermel B, Vogt B, Obermaier-Kusser B, Haring H-U: Hyperglycemiainduced insulin resistance is associated with stimulation of protein kinase $C$ and inhibition of insulin receptor kinase (Abstract). Diabetoloqia 32 (Suppl. 1):485, 1989

57. Obermaier B, Ermel B, Kirsch D, Machicao F, Haring H-U: Catecholamine and tumor-promoting phorbolester inhibit insulin receptor kinase and induce insulin resistance in isolated human adipocytes. Diabetologia 30:93-99, 1987

58. Kirsch $D$, Baumgarten $M$, Denfel T, Rinninger $F$, Kemmler W, Haring $\mathrm{H}-\mathrm{U}$ : Catecholamine-induced insulin resistance of glucose transport in isolated rat adipocytes. Biochem J 216:737-45, 1983

59. Denton RM, Yorke RE, Randle PJ: Measurement of concentrations of metabolites in adipose tissue and effects of insulin, alloxan diabetes, and adrenaline. Biochem J 100:407-91, 1966

60. Okuno $S$, Inaba $M$, Nishizawa $Y$, Inoue $A$, Morii $H$ : Effect of tolbutamide and glyburide on CAMP-dependent protein kinase activity in rat liver cytosol. Diabetes 37:857-61, 1988

61. Osegawa $M$, Makino $H$, Kanatsuka $A$, Kumagai $A$ : Effects of sulfonylureas on membrane-bound low $K_{m}$ cyclic AMP phosphodiesterase in rat fat cells. Biochim Biophys Acta 721:289-96, 1982

62. Begum N, Draznin B: Effect of streptozotocin-induced diabetes on GLUT4 phosphorylation in rat adipocytes. J Clin Invest 90:1254-62, 1992

63. Reusch JE-B, Sussman KE, Draznin B: Inverse relationship between GLUT4 phosphorylation and its intrinsic activity. J Biol Chem 268: 3348-51, 1993

64. Begum N, Leitner W, Reusch JE-B, Sussman KE, Draznin B: GLUT4 phosphorylation and its intrinsic activity: mechanism of $\mathrm{Ca}^{2+}$-induced inhibition of insulin-stimulated glucose transport. $J$ Biol Chem 268:3352-56, 1993

65. Corvera S, Czech MP: Mechanism of insulin action on membrane protein recycling: a selective decrease in the phosphorylation state of insulin-like growth factor II receptors in the cell surface. Proc Natl Acad Sci USA 82:7314-18, 1985

66. Klip A, Marette A: Acute and chronic signals controlling glucose transport in skeletal muscle. J Cell Biochem 48:51-60, 1992

67. Standing VF, Foy JM: The effect of glibenclamide on glucose uptake in the isolated rat diaphragm. Postgrad Med J Supp/5:16-20, 1970

68. Daniels RL, Lewis SB: Acute tolbutamide administration alone or combined with insulin enhances glucose uptake in the perfused rat hindlimb. Endocrinology 110:1840-42, 1982

69. Slot JW, Geuze HJ, Gigengack S, Lienhard GE, James DE: Immunolocalization of the insulin regulatable glucose transporter in brown adipose tissue of the rat. J Cell Biol 113:123-35, 1991

70. Rodnick KJ, Slot JW, Studelska DR, Hanpeter DE, Robinson LJ, Geuze HJ, James DE: Immunocytochemical and biochemical studies of GLUT4 in rat skeletal muscle. J Biol Chem 267:6278-85, 1992

71. Kramer W, Oekonomopulos, Pünter J, Summ H-D: Direct photoaffinity labeling of the putative sulgfonylurea receptor in rat $\beta$-cell tumor membranes by $\left[{ }^{3} \mathrm{H}\right]$ glibenclamide. FEBS Lett 229:355-59, 1988

72. Martz A, Inho J, Jung CY: Sulfonylurea binding to adipocyte membranes and potentiation of insulin-stimulated hexose transport. $J$ Biol Chem 264:13672-78, 1989

73. Rossetti L, Smith D, Shulman GI, Papachristou D, Defronzo RA Correction of hyperglycemia with phlorizin normalizes tissue sensitivity to insulin in diabetic rats. J Clin Invest 79:1510-15, 1987

74. Kahn BB, Shulman GI, DeFronzo RA, Cushman SW, Rossetti L Normalization of blood glucose in diabetic rats with phlorizin treatment reverses insulin-resistant glucose transport in adipose cells without restoring glucose transporter gene expression. J Clin Invest 87:561-70, 1991 